
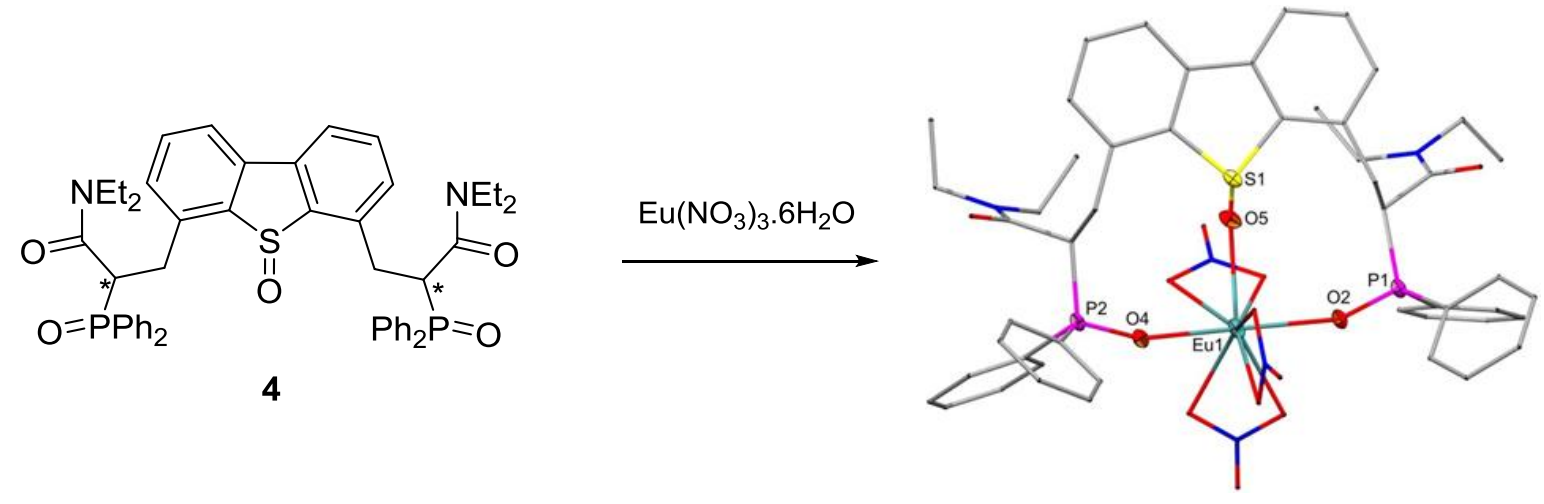

$\left[\mathrm{Eu}(4)\left(\mathrm{NO}_{3}\right)_{3}\right]$ 


\section{Graphical Abstract Synopsis}

New hybrid donor ligands based on the dibenzothiophene and dibenzothiophene-5,5-dioxide platforms decorated with C-attached carbamoylmethylphosphine oxide substituents have been prepared. The potential chelation behavior of the ligands has been explored with molecular mechanics calculations and selected coordination chemistry with $\mathrm{Ln}\left(\mathrm{NO}_{3}\right)_{3}$ salts examined. The acid dependence of the solvent

extraction performance of the dibenzothiophene-5,5-dioxide derivative for Am(III) and Eu(III) has also been surveyed. 


\title{
Synthesis and lanthanide coordination chemistry of CMPO-decorated dibenzothiophene and dibenzothiophene sulfone platforms
}

Daniel Rosario-Amorin ${ }^{\mathrm{a}, 1}$, Sabrina Ouizem ${ }^{\mathrm{a} 2}$, Diane A. Dickie ${ }^{\mathrm{a}}$, Benjamin P. Hay ${ }^{\mathrm{b}}$, Julien Podair ${ }^{\mathrm{c}}$, Laetitia H. Delmau ${ }^{\mathrm{c}}$ and Robert T. Paine ${ }^{\mathrm{a}, *}$

${ }^{\mathrm{a}}$ Department of Chemistry and Chemical Biology, University of New Mexico, Albuquerque, NM 87131, USA

${ }^{\mathrm{b}}$ Supramolecular Design Institute, 127 Chestnut Hill Road, Oak Ridge, TN 37830, USA

${ }^{\mathrm{N}}$ Nuclear Security and Isotope Technology Division, Oak Ridge National Laboratory, P.O. Box 2008, Oak Ridge, TN 37831, USA

\begin{abstract}
Syntheses and spectroscopic characterization data for two new hybrid chelating ligands, 4,6bis[(diphenyl-N,N-diethylcarbamoylmethylphosphine oxide)methyl]dibenzothiophene (2) and 4,6bis[(diphenyl-N,N-diethylcarbamoylmethylphosphine oxide)methyl]dibenzothiophene 5,5-dioxide (3), that contain two CMPO fragments grafted onto dibenzothiophene and dibenzothiophene sulfone platforms, respectively, are presented. Coordination chemistry with selected lanthanide nitrates is described along with a X-ray crystal structure determination for an unexpected $\mathrm{Eu}(\mathrm{III})$ complex, $\mathrm{Eu}(4)\left(\mathrm{NO}_{3}\right)_{3}$ that contains the intermediate ligand oxidation species 4,6-bis[(diphenyl-N,Ndiethylcarbamoylmethylphosphine oxide)methyl]dibenzothiophene 5-oxide (4).
\end{abstract}

Key words: dibenzothiophene, dibenzothiophene sulfone, carbamoylmethylphosphine oxide, lanthanides, X-ray crystallography 


\author{
*Corresponding author. Tel +1 5052771661 \\ E-mail address: rtpaine@unm.edu (R.T.Paine) \\ ${ }^{1}$ Current address: CNRS, CRPP, UPR 8641, F-33600 Pessac, FRANCE \\ ${ }^{2}$ Current address: DIVERCHIM, ZAC du Moulin, 6 rue du Noyer, 95700 Roissy-en-France, FRANCE
}

\title{
1. Introduction
}

A number of organic ring compounds have been used as platforms to append and organize multiple donor groups such that the resulting molecular architectures function as multidentate, chelating receptors for metal ions [1-6]. These include the 4,6-bis $(\mathrm{X})_{2}$ dibenzofuran $(\mathbf{A})$ and 4,6-bis $(\mathrm{X})_{2}$ dibenzothiophene $(\mathbf{B})$ platforms (Figure 1) that have been employed to construct both acyclic and macrocyclic multi-functional ligands especially suited for binding with soft transition metals of interest in catalyst designs [7-26]. Primarily in support of efforts to develop efficient, selective recognition reagents and separation processes for hard $f$-element ions present in nuclear waste solutions, parallel efforts to prepare appropriately preorganized harder donor group-decorated assemblies have taken place, and much of that work has been reviewed [27-33]. Relevant to those activities and to the present contribution, syntheses for trifunctional hybrid ligands of types $\mathbf{C}-\mathbf{E}$, that combine the $\mathbf{A}$ and $\mathbf{B}$ platforms with phosphine oxide donor groups, have also recently been reported [34,35] along with studies of their coordination chemistry with trivalent lanthanides. With these hard ions, both $\mathbf{C}$ and $\mathbf{D}$ are observed to form only bidentate $\mathrm{O}_{\mathrm{P}} \mathrm{O}_{\mathrm{P}}$ chelate structures in which the soft, weakly basic furan-O and thiophene-S donor sites remain coordination silent. On the other hand, a sulfone derivative, $\mathbf{E}$, produces tridentate $\mathrm{O}_{\mathrm{P}} \mathrm{O}_{\mathrm{S}} \mathrm{O}_{\mathrm{P}}$ chelate structures. Pyridine and pyridine $\mathrm{N}$-oxide platforms have also been used extensively to assemble multiple donor groups, and we have reported in the past on the development of ligands of type $\mathbf{F}$ that behave as strong, tridentate lanthanide and actinide ion chelators and solvent extraction reagents [36,37]. Since carbamoylmethyl phosphine oxides, CMPOs, $\mathbf{G}$, are also known to be effective ligands and extractants for $f$-element ions $[38,39]$, several approaches for the assembly of multiple CMPO fragments on a single platform have been 
explored and that work has been reviewed [ 27, 40]. In this regard, F- and G-ligand types have recently been combined through $\mathrm{C}$-atom attachment to provide examples of potential pentadenate chelators, $\mathbf{H}$ and I [41]. A family of $\mathrm{N}$-attached ligands has also been reported [42]. These three ligand types produce novel coordination complex structures with lanthanide ions, and examples of $\mathbf{H}$ are especially good extractants for $f$-element cations in nitric acid solutions. Extending these studies, we report here on the combination of the B-type platform and its sulfone derivative with the carbamoylmethylphosphine oxide (CMPO), G, ligand fragment.

[Insert Figure 1 near here]

\section{Experimental}

\subsection{Material and general procedures}

Organic reagents (Aldrich Chemical Co.) and metal salts (Ventron) were used as received, and organic solvents (VWR) were dried by using standard methods. Reactions were performed under a dry nitrogen atmosphere by using Schlenk methods unless noted otherwise. Infrared spectra were recorded on a Bruker Tensor 27 FT-IR spectrometer from KBr pellets. The FT-NMR spectra were obtained with Avance 300 and 500 spectrometers by using $\mathrm{Me}_{4} \mathrm{Si}\left({ }^{1} \mathrm{H}\right.$ and $\left.{ }^{13} \mathrm{C}\right)$ and $85 \% \mathrm{H}_{3} \mathrm{PO}_{4}$ as external chemical shift standards, and downfield shifts from the reference signal were assigned $+\delta$ values. The $\mathrm{H}$ - and $\mathrm{C}$-atom numbering schemes employed in the chemical shift assignment tabulations for each organic compound are provided

in the Supplementary Data. High resolution mass spectra (HRMS) were recorded at the UNM Mass Spectrometry Center, and elemental analyses were performed by Galbraith Laboratories.

\subsection{Experimental procedures}

\subsubsection{Ligand syntheses}




\subsubsection{4,6-bis[(diphenyl-N,N-diethylcarbamoylmethylphosphine oxide)methyl]dibenzothiophene (2). A} solution of $n$-BuLi $(1.6 \mathrm{M}$ in hexane, $9.30 \mathrm{~mL}, 14.9 \mathrm{mmol})$ was added dropwise $\left(23{ }^{\circ} \mathrm{C}, 30 \mathrm{~min}\right)$ to a vigorously stirred solution of diphenyl-N,N-diethylcarbamoylmethylphosphine oxide $\left(\mathbf{G} ; \mathrm{R}=\mathrm{R}\right.$ ' $=\mathrm{Ph}, \mathrm{R}^{\prime}$ $=\mathrm{Et})(4.70 \mathrm{~g}, 14.9 \mathrm{mmol})$ in toluene $(50 \mathrm{~mL})$. Following combination of the reagents, a clear, pale yellow solution was obtained that was heated $\left(85^{\circ} \mathrm{C}, 2 \mathrm{~h}\right)$ and stirred. The resulting dark red solution was cooled $\left(\begin{array}{ll}0 & { }^{\circ} \mathrm{C}\end{array}\right)$, transferred dropwise over $1 \mathrm{~h}$ into a vigorously stirred solution of 4,6bis(chloromethyl)dibenzothiophene (1) [35] $(1.40 \mathrm{~g}, 4.98 \mathrm{mmol})$ in toluene $\left(50 \mathrm{~mL}, 0{ }^{\circ} \mathrm{C}\right)$, and the combination was then heated $\left(85^{\circ} \mathrm{C}\right)$ and stirred $(12 \mathrm{~h})$. The resulting mixture was cooled, diluted with $\mathrm{CH}_{2} \mathrm{Cl}_{2}(150 \mathrm{~mL})$, and the organic phase washed with brine $(2 \times 30 \mathrm{~mL})$ and water $(3 \times 30 \mathrm{~mL})$. The organic phase was evaporated to dryness leaving a light brown residue that was washed with $\mathrm{Et}_{2} \mathrm{O}(3 \times 30$ $\mathrm{mL})$. The resulting white powder was dissolved in a mixture of $\mathrm{MeOH}: \mathrm{CH}_{2} \mathrm{Cl}_{2}(1: 1,3 \mathrm{~mL})$ and $\mathrm{Et}_{2} \mathrm{O}$ $(150 \mathrm{~mL})$, and the clear solution was concentrated by slow evaporation $\left(18 \mathrm{~h}, 23^{\circ} \mathrm{C}\right)$ until colorless blocklike crystals of $\mathbf{2}$ started to form. These were immediately collected by filtration and washed with $\mathrm{Et}_{2} \mathrm{O}$ ( 3 x $5 \mathrm{~mL}$ ). Yield: $0.71 \mathrm{~g}, 17 \%$ (meso/rac $>97 / 3$ ). The remaining mother liquor was evaporated to dryness, and the residue was purified by column chromatography (silica gel, $\mathrm{CH}_{2} \mathrm{Cl}_{2}: \mathrm{MeOH}, 98: 2$ ) providing a diasteroisomeric mixture of 2. Yield: $1.91 \mathrm{~g}, 46 \%$ (meso/rac 29/71). Global yield: $2.62 \mathrm{~g}, 63 \%$ (meso/rac 47/53). ${ }^{31} \mathrm{P}\left\{{ }^{1} \mathrm{H}\right\}$ NMR (121.5 MHz, $\left.\mathrm{CDCl}_{3}\right)$ meso-2: $\delta=30.2 ;$ rac-2: $\delta=30.2 .{ }^{1} \mathrm{H} \mathrm{NMR}(300 \mathrm{MHz}$, $\left.\mathrm{CDCl}_{3}\right)$ meso-2: $\delta=8.27-8.21\left(\mathrm{~m}, 4 \mathrm{H}, H_{10}\right), 7.95-7.90\left(\mathrm{~m}, 4 \mathrm{H}, H_{10}\right), 7.82\left(\mathrm{~d}, J_{H H}=6.9 \mathrm{~Hz}, 2 \mathrm{H}, H_{4}\right), 7.53-$ $7.44\left(\mathrm{~m}, 12 \mathrm{H}, H_{\left.11,11^{\prime}, 12,12^{\prime}\right)}\right), 7.24-7.17\left(\mathrm{~m}, 4 \mathrm{H}, H_{2,3}\right), 4.07$ (pseudo t, $\left.J_{H P}=11.8 \mathrm{~Hz}, 2 \mathrm{H}, H_{8}\right), 3.69-3.58(\mathrm{~m}$, $\left.2 \mathrm{H}, H_{7 a}\right), 3.36-3.28\left(\mathrm{~m}, 2 \mathrm{H}, H_{7 b}\right), 3.13-3.02\left(\mathrm{~m}, 2 \mathrm{H}, H_{14}\right), 2.96-2.76\left(\mathrm{~m}, 4 \mathrm{H}, H_{14,14^{\prime}}\right), 2.46-2.35(\mathrm{~m}, 2 \mathrm{H}$, $\left.H_{14^{\prime}}\right), 0.66\left(\mathrm{t}, J_{H H}=7.0 \mathrm{~Hz}, 6 \mathrm{H}, H_{15}\right), 0.22\left(\mathrm{t}, J_{H H}=7.0 \mathrm{~Hz}, 6 \mathrm{H}, H_{15}\right) ; r a c-2: \delta=8.33-8.29\left(\mathrm{~m}, 4 \mathrm{H}, H_{10}\right)$, 7.96-7.91 (m, 4H, $\left.H_{10}\right), 7.86\left(\mathrm{~d}, J_{H H}=6.5 \mathrm{~Hz}, 2 \mathrm{H}, H_{4}\right), 7.54-7.47\left(\mathrm{~m}, 12 \mathrm{H}, H_{11,11}, 12,12^{\prime}\right), 7.23-7.21(\mathrm{~m}, 4 \mathrm{H}$, $\left.H_{2,3}\right), 4.07$ (pseudo t, $\left.J_{H P}=12.1 \mathrm{~Hz}, 2 \mathrm{H}, H_{8}\right), 3.68-3.58\left(\mathrm{~m}, 2 \mathrm{H}, H_{7 a}\right), 3.40-3.35\left(\mathrm{~m}, 2 \mathrm{H}, H_{7 b}\right), 3.12-2.79$ $\left(\mathrm{m}, 4 \mathrm{H}, H_{14}\right), 2.70-2.62\left(\mathrm{~m}, 2 \mathrm{H}, H_{14}\right), 2.33-2.24\left(\mathrm{~m}, 2 \mathrm{H}, H_{14}\right), 0.66\left(\mathrm{t}, J_{H H}=6.9 \mathrm{~Hz}, 6 \mathrm{H}, H_{15}\right), 0.10\left(\mathrm{t}, J_{H H}\right.$ $\left.=6.9 \mathrm{~Hz}, 6 \mathrm{H}, H_{15}\right) .{ }^{13} \mathrm{C}\left\{{ }^{1} \mathrm{H}\right\} \operatorname{NMR}\left(75.5 \mathrm{MHz}, \mathrm{CDCl}_{3}\right)$ meso-2: $\delta=167.4\left(C_{13}\right), 138.0\left(C_{6}\right), 136.2\left(C_{5}\right)$, 
$133.1\left(\mathrm{~d}, J_{C P}=14.2 \mathrm{~Hz}, C_{1}\right), 132.2-131.6\left(\mathrm{~m}, C_{10,10^{\prime}, 12,12^{\prime}}\right), 131.0\left(\mathrm{~d}, J_{C P}=99.6 \mathrm{~Hz}, C_{9,9^{\prime}}\right), 128.5\left(\mathrm{~d}, J_{C P}=\right.$ $\left.11.6 \mathrm{~Hz}, C_{11}\right), 128.3\left(\mathrm{~d}, J_{C P}=11.4 \mathrm{~Hz}, C_{11}\right), 128.0\left(C_{2}\right), 124.8\left(C_{3}\right), 120.1\left(C_{4}\right), 46.2\left(\mathrm{~d}, J_{C P}=60.6 \mathrm{~Hz}\right.$, $\left.C_{8}\right), 42.1\left(C_{14^{\prime}}\right), 40.8\left(C_{14}\right), 33.6\left(C_{7}\right), 13.4\left(C_{15}\right), 12.4\left(C_{15}\right) ;$ rac-2: $\delta=167.4\left(C_{13}\right), 138.0\left(C_{6}\right), 136.3$ $\left(C_{5}\right), 133.1\left(\mathrm{~d}, J_{C P}=14.2 \mathrm{~Hz}, C_{l}\right), 132.2-131.8\left(\mathrm{~m}, C_{10,10^{\prime}, 12,12^{\prime}}\right), 131.0\left(\mathrm{~d}, J_{C P}=104.6 \mathrm{~Hz}, C_{9,9}\right), 128.7-$ $128.3\left(\mathrm{~m}, C_{11,11^{\prime}}\right), 128.3\left(C_{2}\right), 124.9\left(C_{3}\right), 120.2\left(C_{4}\right), 46.1\left(\mathrm{~d}, J_{C P}=60.5 \mathrm{~Hz}, C_{8}\right), 42.3\left(C_{14^{\prime}}\right), 40.9\left(C_{14}\right)$, $33.8\left(C_{7}\right), 13.3\left(C_{15}\right), 12.5\left(C_{15}\right)$. IR $\left(\mathrm{KBr}, \mathrm{cm}^{-1}\right): 3055,2972,2932,1630\left(v_{\mathrm{CO}}\right), 1589,1572,1483,1461$, $1389,1360,1320,1205\left(v_{\mathrm{PO}}\right), 1167,1116,1099,1072,1046,1027,996,952,902,878,859,833,780$, 755, 726, 701, 630, 604, 535, 509. HRMS(ESI): $\mathrm{m} / z(\%): 839.3221$ (12) $\left[\mathrm{M}+\mathrm{H}^{+}\right] . \mathrm{C}_{50} \mathrm{H}_{53} \mathrm{~N}_{2} \mathrm{O}_{4} \mathrm{P}_{2} \mathrm{~S}$ requires 839.3201; $861.3040(100)\left[\mathrm{M}+\mathrm{Na}^{+}\right] . \mathrm{C}_{50} \mathrm{H}_{52} \mathrm{~N}_{2} \mathrm{O}_{4} \mathrm{P}_{2} \mathrm{SNa}$ requires 861.3021. Anal. Calcd for $\mathrm{C}_{50} \mathrm{H}_{52} \mathrm{~N}_{2} \mathrm{O}_{4} \mathrm{P}_{2} \mathrm{~S} \cdot\left(\mathrm{H}_{2} \mathrm{O}\right):$ C 70.08, H 6.35, N 3.27. Found: C 69.31, H 6.01, N 3.11.

\subsubsection{4,6-bis[(diphenyl-N,N-diethylcarbamoylmethylphosphine oxide)methyl]dibenzothiophene 5,5-} dioxide (3). To a solution of 2 (1.00 g, $1.19 \mathrm{mmol}$, meso/rac 29/71) in anhydrous $\mathrm{CH}_{2} \mathrm{Cl}_{2}(15 \mathrm{~mL})$, was slowly added $m$-chloroperoxybenzoic acid (77 wt $\%, 1.07 \mathrm{~g}, 4.78 \mathrm{mmol})$, and the combination was stirred $\left(23^{\circ} \mathrm{C}, 12 \mathrm{~h}\right)$. The resulting mixture was diluted with $\mathrm{CH}_{2} \mathrm{Cl}_{2}(50 \mathrm{~mL})$ and then washed with aqueous $\mathrm{NaOH}(2 \mathrm{~N}, 3 \times 15 \mathrm{~mL})$ and distilled water $(2 \times 15 \mathrm{~mL})$. The organic phase was dried (anhydr. $\left.\mathrm{MgSO}_{4}\right)$, filtered, and the volatiles were removed by vacuum evaporation leaving $\mathbf{3}$ as a white powder. Yield: 955 mg, 92\% (meso/rac 29/71). Diastereomerically pure meso-3 was prepared in similar manner starting with meso-2. ${ }^{31} \mathrm{P}\left\{{ }^{1} \mathrm{H}\right\}$ NMR $\left(121.5 \mathrm{MHz}, \mathrm{CDCl}_{3}\right)$ meso-3: $\delta=30.7 ;$ rac-3: $\delta=30.3 .{ }^{1} \mathrm{H}$ NMR $(300 \mathrm{MHz}$, $\left.\mathrm{CDCl}_{3}\right)$ meso-3: $\delta=8.05-7.92\left(\mathrm{~m}, 8 \mathrm{H}, H_{10,10^{\prime}}\right), 7.47\left(\mathrm{~m}, 14 \mathrm{H}, H_{4,11,11}, 12,12^{\prime}\right), 7.35-7.26\left(\mathrm{~m}, 4 \mathrm{H}, H_{2,3}\right), 4.54$ $\left(\mathrm{ddd}, J_{H P}=11.6 \mathrm{~Hz} ; J_{H H}=7.5 \mathrm{~Hz}, 2 \mathrm{H}, H_{8}\right), 3.76-3.68\left(\mathrm{~m}, 2 \mathrm{H}, H_{7 a}\right), 3.53-3.40\left(\mathrm{~m}, 2 \mathrm{H}, H_{7 b}\right), 3.16-2.90(\mathrm{~m}$, $\left.6 \mathrm{H}, H_{14,14^{\prime}}\right), 2.73-2.66\left(\mathrm{~m}, 2 \mathrm{H}, H_{14^{\prime}}\right), 0.71\left(\mathrm{t}, J_{H H}=7.0 \mathrm{~Hz}, 6 \mathrm{H}, H_{15}\right), 0.49\left(\mathrm{t}, J_{H H}=6.9 \mathrm{~Hz}, 6 \mathrm{H}, H_{15}\right) ; r a c-$ 3: $\delta=8.07-7.97\left(\mathrm{~m}, 8 \mathrm{H}, H_{10,10^{\prime}}\right), 7.51-7.46\left(\mathrm{~m}, 14 \mathrm{H}, H_{4,11,11}, 12,12^{\prime}\right), 7.34-7.29\left(\mathrm{~m}, 4 \mathrm{H}, H_{2,3}\right), 4.54\left(\mathrm{ddd}, J_{H P}\right.$ $\left.=11.9 \mathrm{~Hz} ; J_{H H}=8.6 \mathrm{~Hz}, 2 \mathrm{H}, H_{8}\right), 3.78-3.98\left(\mathrm{~m}, 2 \mathrm{H}, H_{7 a}\right), 3.53-3.42\left(\mathrm{~m}, 2 \mathrm{H}, H_{7 b}\right), 3.13-2.90(\mathrm{~m}, 6 \mathrm{H}$, $\left.H_{14,14^{\prime}}\right), 2.65-2.56\left(\mathrm{~m}, 2 \mathrm{H}, H_{14^{\prime}}\right), 0.70\left(\mathrm{t}, J_{H H}=6.9 \mathrm{~Hz}, 6 \mathrm{H}, H_{15}\right), 0.40\left(\mathrm{t}, J_{H H}=7.0 \mathrm{~Hz}, 6 \mathrm{H}, H_{15}\right) .{ }^{13} \mathrm{C}\left\{{ }^{1} \mathrm{H}\right\}$ $\operatorname{NMR}\left(75.5 \mathrm{MHz}, \mathrm{CDCl}_{3}\right)$ meso-3: $\delta=166.9\left(C_{13}\right), 136.3\left(\mathrm{~d}, J_{C P}=15.1 \mathrm{~Hz}, C_{l}\right), 135.5\left(C_{6}\right), 134.1\left(C_{3}\right)$, 
$133.5\left(C_{2}\right), 132.2-132.1\left(\mathrm{~m}, C_{10,10^{\prime}, 12,12^{\prime}}\right), 131.5\left(\mathrm{~d}, J_{C P}=103.4 \mathrm{~Hz}, C_{9}\right), 131.4\left(C_{5}\right), 130.7\left(\mathrm{~d}, J_{C P}=102.7\right.$ $\left.\mathrm{Hz}, C_{9}\right), 128.5\left(\mathrm{~d}, J_{C P}=12.1 \mathrm{~Hz}, C_{11}\right), 128.4\left(\mathrm{~d}, J_{C P}=12.1 \mathrm{~Hz}, C_{11^{\prime}}\right), 120.0\left(C_{4}\right), 45.8\left(\mathrm{~d}, J_{C P}=60.6 \mathrm{~Hz}\right.$, $\left.C_{8}\right), 42.3\left(C_{14}\right), 40.8\left(C_{14}\right), 29.9\left(C_{7}\right), 13.9\left(C_{15}\right), 12.6\left(C_{15}\right) ;$ rac-3: $\delta=166.8\left(C_{13}\right), 136.3\left(\mathrm{~d}, J_{C P}=15.1\right.$ $\left.\mathrm{Hz}, C_{l}\right), 135.5\left(C_{6}\right), 134.1\left(C_{3}\right), 133.5\left(C_{2}\right), 132.2-132.0\left(\mathrm{~m}, C_{10,10^{\prime}, 12,12^{\prime}}\right), 131.4\left(C_{5}\right), 131.4\left(\mathrm{~d}, J_{C P}=99.1\right.$ $\left.\mathrm{Hz}, C_{9}\right), 130.9\left(\mathrm{~d}, J_{C P}=99.1 \mathrm{~Hz}, C_{9}\right), 128.6-128.3\left(\mathrm{~m}, C_{11,11}\right), 120.0\left(C_{4}\right), 45.7\left(\mathrm{~d}, J_{C P}=59.3 \mathrm{~Hz}, C_{8}\right)$, $42.2\left(C_{14^{\prime}}\right), 40.6\left(C_{14}\right), 29.8\left(C_{7}\right), 13.8\left(C_{15^{\prime}}\right), 12.6\left(C_{15}\right) . \mathrm{IR}\left(\mathrm{KBr}, \mathrm{cm}^{-1}\right): 3071,2974,2932,1635\left(v_{\mathrm{CO}}\right)$, $1583,1479,1435,1380,1360,1317,1290\left(v_{\mathrm{SO}(\text { as })}\right), 1261,1184\left(v_{\mathrm{PO}}\right), 1157\left(v_{\mathrm{SO}(\mathrm{sy})}\right), 1115,1097,1070$ $1046,997,880,833,798,746,719,702,629,596,557,513$. HRMS(ESI): $m / z(\%): 871.3113(19)[\mathrm{M}+$ $\left.\mathrm{H}^{+}\right] . \mathrm{C}_{50} \mathrm{H}_{53} \mathrm{~N}_{2} \mathrm{O}_{6} \mathrm{P}_{2} \mathrm{~S}$ requires 871.3100; 893.2914 (100) $\left[\mathrm{M}+\mathrm{Na}^{+}\right] . \mathrm{C}_{50} \mathrm{H}_{52} \mathrm{~N}_{2} \mathrm{O}_{6} \mathrm{P}_{2} \mathrm{SNa}$ requires 893.2919. Anal. Calcd for $\mathrm{C}_{50} \mathrm{H}_{52} \mathrm{~N}_{2} \mathrm{O}_{6} \mathrm{P}_{2} \mathrm{~S} \cdot\left(\mathrm{H}_{2} \mathrm{O}\right)_{2}$ : C 66.21, H 6.22, N 3.09. Found: C 66.68, H 6.10 N 3.01.

\subsubsection{Lanthanide Complex Syntheses.}

The lanthanide coordination complexes were prepared by combination of one equivalent of ligand (50 mg) with one equivalent of $\mathrm{Ln}\left(\mathrm{NO}_{3}\right)_{3} \cdot x \mathrm{H}_{2} \mathrm{O}$ in $\mathrm{MeOH}$. The mixtures were stirred $\left(23{ }^{\circ} \mathrm{C}, 2 \mathrm{~h}\right)$, volatiles removed by vacuum evaporation, and the resulting powders were vacuum dried. Elemental analyses (CHN), infrared spectra and selected NMR spectra for several samples were obtained, and representative data are summarized as follows. [ $\left.\mathrm{La}(2)\left(\mathrm{NO}_{3}\right)_{3}\right]: \mathrm{IR}\left(\mathrm{KBr}, \mathrm{cm}^{-1}\right): 1592\left(v_{\mathrm{CO}}\right), 1150\left(v_{\mathrm{PO}}\right)$. Anal. Calcd for $\left[\mathrm{C}_{50} \mathrm{H}_{52} \mathrm{LaN}_{5} \mathrm{O}_{13} \mathrm{P}_{2} \mathrm{~S}\right] \cdot 5\left(\mathrm{H}_{2} \mathrm{O}\right): \mathrm{C} 47.89, \mathrm{H}$ 4.98, N 5.58. Found: $\mathrm{C} 46.07, \mathrm{H} 3.45, \mathrm{~N}$ 6.02. $\left[\operatorname{Pr}(2)\left(N O_{3}\right)_{3}\right]:$ IR $\left(\mathrm{KBr}, \mathrm{cm}^{-1}\right): 1597\left(v_{\mathrm{CO}}\right), 1151\left(v_{\mathrm{PO}}\right) . \quad\left[E u(2)\left(N O_{3}\right)_{3}\right]:$ IR $\left(\mathrm{KBr}, \mathrm{cm}^{-1}\right): 1601\left(v_{\mathrm{CO}}\right), 1150\left(v_{\mathrm{PO}}\right)$. [Er(2)(NO$\left.)_{3}\right]:$ IR $\left(\mathrm{KBr}, \mathrm{cm}^{-1}\right): 1598\left(v_{\mathrm{CO}}\right), 1149\left(v_{\mathrm{PO}}\right) .\left[\mathrm{Lu}(2)\left(\mathrm{NO}_{3}\right)_{3}\right]$ (with meso-2 for NMR analyses): ${ }^{31} \mathrm{P}\left\{{ }^{1} \mathrm{H}\right\}$ NMR $\left(121.5 \mathrm{MHz}, d_{4}-\mathrm{MeOH}\right): \delta=38.6 .{ }^{1} \mathrm{H}$ NMR $\left(300 \mathrm{MHz}, d_{4}-\mathrm{MeOH}\right): \delta=8.18-8.00(\mathrm{~m}$, $\left.10 \mathrm{H}, H_{4,10,10^{\prime}}\right), 7.69-7.63\left(\mathrm{~m}, 12 \mathrm{H}, H_{11,11^{\prime}, 12,12^{\prime}}\right), 7.34-7.23\left(\mathrm{~m}, 4 \mathrm{H}, H_{2,3}\right), 4.37$ (pseudo t, $J_{H P}=9.9 \mathrm{~Hz}, 2 \mathrm{H}$, $\left.H_{8}\right), 3.75-3.65\left(\mathrm{~m}, 2 \mathrm{H}, H_{7 a}\right), 3.21-3.10\left(\mathrm{~m}, 4 \mathrm{H}, H_{7 b, 14}\right), 3.04-2.96\left(\mathrm{~m}, 2 \mathrm{H}, H_{14}\right), 2.89-2.81\left(\mathrm{~m}, 2 \mathrm{H}, H_{14^{\prime}}\right)$, 2.65-2.57 (m, 2H, $\left.\left.H_{14}\right), 0.64\left(\mathrm{t}, J_{H H}=6.9 \mathrm{~Hz}, 6 \mathrm{H}, H_{15}\right), 0.18\left(\mathrm{t}, J_{H H}=7.0 \mathrm{~Hz}, 6 \mathrm{H}, H_{15}\right)^{\prime}\right) \mathrm{IR}\left(\mathrm{KBr}, \mathrm{cm}^{-1}\right)$ : $1596\left(v_{\mathrm{CO}}\right), 1147\left(v_{\mathrm{PO}}\right)$. [La(3)(NO $\left.)_{3}\right]$ : IR $\left(\mathrm{KBr}, \mathrm{cm}^{-1}\right): 1601\left(v_{\mathrm{CO}}\right), 1290\left(\mathrm{br}, v_{\mathrm{SO}(\mathrm{as})}\right), 1155\left(\mathrm{br}, v_{\mathrm{PO}}, v_{\mathrm{SO}}\right)$. Anal. Calcd for $\left\{\mathrm{C}_{50} \mathrm{H}_{52} \mathrm{LaN}_{5} \mathrm{O}_{15} \mathrm{P}_{2} \mathrm{~S}\right] \cdot 3(\mathrm{MeOH}) \cdot 2\left(\mathrm{H}_{2} \mathrm{O}\right)$ : C 49.19, H 5.14, N 5.41. Found: C 46.31, H 
3.64, N 3.67. $\left[\operatorname{Pr}(3)\left(\mathrm{NO}_{3}\right)_{3}\right]$ : IR $\left(\mathrm{KBr}, \mathrm{cm}^{-1}\right): 1601\left(v_{\mathrm{CO}}\right), 1294\left(\mathrm{br}, v_{\mathrm{SO}(\mathrm{as})}\right), 1155$ (br, $\left.v_{\mathrm{PO},} v_{\mathrm{SO}}\right)$. [Eu(3)(NO $\left.)_{3}\right]$ : IR $\left(\mathrm{KBr}, \mathrm{cm}^{-1}\right): 1603\left(v_{\mathrm{CO}}\right), 1290\left(\mathrm{br}, v_{\mathrm{SO}(\mathrm{as})}\right), 1155\left(\mathrm{br}, v_{\mathrm{PO}}, v_{\mathrm{SO}}\right) .\left[\operatorname{Er}(3)\left(N O_{3}\right)_{3}\right]: \mathrm{IR}(\mathrm{KBr}$, $\left.\mathrm{cm}^{-1}\right): 1605\left(v_{\mathrm{CO}}\right), 1294\left(\mathrm{br}, v_{\mathrm{SO}(\mathrm{as})}\right), 1155\left(\mathrm{br}, v_{\mathrm{PO}}, v_{\mathrm{SO}}\right) .\left[\mathrm{Lu}(\mathbf{3})\left(\mathrm{NO}_{3}\right)_{3}\right]$ (with 3 (rac/meso 71/29) for NMR analyses): ${ }^{31} \mathrm{P}\left\{{ }^{1} \mathrm{H}\right\}$ NMR $\left(121.5 \mathrm{MHz}, d_{4}-\mathrm{MeOH}\right): \delta=38.3 .{ }^{1} \mathrm{H}$ NMR $\left(300 \mathrm{MHz}, d_{4}-\mathrm{MeOH}\right): \delta=8.19-$ $7.83\left(\mathrm{~m}, 10 \mathrm{H}, H_{4,10,10^{\circ}}\right), 7.77-7.51\left(\mathrm{~m}, 14 \mathrm{H}, H_{3,11,11,12,12}\right), 7.40-7.33\left(\mathrm{~m}, 2 \mathrm{H}, H_{2}\right), 4.77\left(\mathrm{~m}, 1.4 \mathrm{H}, H_{8(\mathrm{rac})}\right)$, $4.63\left(\mathrm{~m}, 0.6 \mathrm{H}, H_{8(m e s o)}\right), 3.72-3.62\left(\mathrm{~m}, 4 \mathrm{H}, H_{7 a, b}\right), 3.30-2.86\left(\mathrm{~m}, 8 \mathrm{H}, H_{14,14}\right), 0.78\left(\mathrm{t}, J_{H H}=7.0 \mathrm{~Hz}, 6 \mathrm{H}\right.$, $\left.H_{15}\right), 0.42\left(\mathrm{t}, J_{H H}=7.0 \mathrm{~Hz}, 1.8 \mathrm{H}, H_{15^{\prime}(\text { meso })}\right), 0.42\left(\mathrm{t}, J_{H H}=7.0 \mathrm{~Hz}, 4.2 \mathrm{H}, H_{15^{\prime}(\text { (rac })}\right) . \mathrm{IR}\left(\mathrm{KBr}, \mathrm{cm}^{-1}\right): 1607$ $\left(v_{\mathrm{CO}}\right), 1292\left(\mathrm{br}, v_{\mathrm{SO}(\mathrm{as})}\right), 1153\left(\mathrm{br}, v_{\mathrm{PO}}, v_{\mathrm{SO}}\right) .\left[E u(4)\left(N_{3}\right)_{3}\right]: \mathrm{IR}\left(\mathrm{KBr}, \mathrm{cm}^{-1}\right): 1635\left(v_{\mathrm{CO}}\right), 1149\left(v_{\mathrm{PO}}\right), 972$ $\left(v_{\mathrm{SO}}\right)$. Anal. Calcd for $\left[\mathrm{C}_{50} \mathrm{H}_{52} \mathrm{EuN}_{5} \mathrm{O}_{14} \mathrm{P}_{2} \mathrm{~S}\right] \cdot 5\left(\mathrm{H}_{2} \mathrm{O}\right): \mathrm{C} 46.81, \mathrm{H} 4.87, \mathrm{~N}$ 5.46. Found $\mathrm{C} 44.71, \mathrm{H} 3.28, \mathrm{~N}$ 4.05 .

\subsubsection{Single crystal $X$-ray diffraction analyses}

Single crystals of meso-2. $2 \mathrm{MeOH}$ and $\left[\mathrm{Eu}(\mathbf{4})\left(\mathrm{NO}_{3}\right)_{3}\right]$ were obtained, and specimens (colorless block, $0.221 \times 0.316 \times 0.416 \mathrm{~mm}$ and colorless rod-like $0.061 \times 0.101 \times 0.280 \mathrm{~mm}$, respectively) were coated with Paratone oil and mounted on a MiTeGen support attached to a metallic pin using epoxy. The X-ray diffraction data were collected with a Bruker APEX II CCD system equipped with a graphite monochromator, MoK $\alpha$ sealed X-ray tube $(\lambda=0.71073 \AA)$ and Oxford Cryostream 700 low temperature device. Full spheres of diffraction data were collected, integrated [43] and processed with the Bruker APEX2 software suite [44] including corrections for absorption (SADABS) [45]. The structures were solved by direct methods and refined with full-matrix least-squares on $\mathrm{F}^{2}$ using SHELXTL [46]. Selected crystal data are provided in Table 1. The non-hydrogen atom positions were refined anisotropically although constraints were placed on the thermal displacement parameters of one ethyl group (C37 and C38) of the ligand in $\left[\mathrm{Eu}(4)\left(\mathrm{NO}_{3}\right)_{3}\right]$. H-atoms were placed in geometrically calculated positions and refined with $U_{i s o}=1.2 U_{e q}$ of the parent atom except for $\mathrm{H} 5$ in $m e s o-2 \cdot 2 \mathrm{MeOH}$, that was located in the diffraction map, the $\mathrm{H}$-atoms on methyl groups, in both compounds, and the $\mathrm{O}-\mathrm{H}$ hydrogen atoms in meso-2 $2 \mathrm{MeOH}$. These were refined with $U_{i s o}=1.5 U_{e q}$ of the parent atom. Disordered solvent molecules 
in $\left[\mathrm{Eu}(4)\left(\mathrm{NO}_{3}\right)_{3}\right]$ could not be adequately modeled, and they were treated with SQUEEZE $[47,48]$ which found a solvent-accessible void space of $142 \AA^{3}$ containing $64 \mathrm{e}^{-}$.

\subsubsection{Molecular Mechanics Calculations}

Geometry optimizations of free and lanthanide-bound structures of $2, \mathbf{3}$ and $\mathbf{4}$ were accomplished with a MM3 force field [49-51] by using a points-on-a-sphere metal ion [52] as implemented in PCModel software [53]. Conformational searches to locate the most stable form for each structure were performed with the GMMX algorithm provided in this software.

\subsubsection{Distribution Studies.}

Extraction experiments were carried out using 1,2-dichloroethane (OmniSolv, EM Science) as the diluent. The aqueous phases were prepared using nitric acid (J. T. Baker, Ultrex II) and europium nitrate (Aldrich, 99.9\%). Distilled, deionized water was obtained from a Barnstead Nanopure filter system (resistivity at least $18.2 \mathrm{M} \Omega-\mathrm{cm}$ ) and used to prepare all the aqueous solutions. The radioisotope ${ }^{241} \mathrm{Am}$ was provided by the Radiochemical and Engineering Research Center (REDC) of ORNL. The radiotracer ${ }^{152 / 154} \mathrm{Eu}$ was obtained from Isotope Products, Burbank, CA. Caution! Tracer solutions containing ${ }^{241}$ Am and ${ }^{152 / 154}$ Eu are radioactive. All chemical manipulations with these isotopes must be conducted in an appropriate radiological laboratory following all necessary controls and regulations. Both isotopes were added as spikes to the aqueous phases in the sample equilibration vials in the extraction experiments. Phases with a 1:1 organic to aqueous (O:A) phase ratio were combined in $2 \mathrm{~mL}$ polypropylene microtubes, which were then capped and mounted by clips on a disk that was rotated in a constant-temperature air box at $25.0 \pm 0.5{ }^{\circ} \mathrm{C}$ for 1 hour. After the contacting period, the tubes were centrifuged for 5 min at $3000 \mathrm{RPM}$ and $25^{\circ} \mathrm{C}$ in a Beckman Coulter ${ }^{\mathrm{TM}}$ Allegra 6R temperature-controlled centrifuge. A $250 \mu \mathrm{L}$ aliquot of each phase was sub-sampled and counted using a Canberra Analyst pure Ge Gamma counter. Counting times were sufficient to ensure that counting error was a small fraction of the precision of the obtained distribution ratios, considered from a combination of volumetric, replicate and counting errors to 
be $\pm 5 \%$. Americium and europium distribution ratios were calculated as the ratio of the volumetric count rates of the ${ }^{241} \mathrm{Am}$ and ${ }^{152 / 154} \mathrm{Eu}$ isotopes in each phase at equilibrium.

\section{Results and discussion}

\subsection{Ligand synthesis and characterization}

The synthesis of 4,6-bis[(diphenyl-N,N-diethylcarbamoylmethylphosphine oxide)methyl]dibenzothiophene, $\mathbf{2}$, was accomplished in two steps as depicted in Scheme 1. The CMPO compound, diphenyl-N,N-diethylcarbamoyl methylphosphine oxide, 1, was first combined with $n$-BuLi in toluene at $23{ }^{\circ} \mathrm{C}$, and the mixture was heated and stirred at $85^{\circ} \mathrm{C}$. The resulting red solution containing the putative species $\mathrm{Li}_{2}\left[\mathrm{Ph}_{2} \mathrm{P}(\mathrm{O}) \mathrm{CHC}(\mathrm{O}) \mathrm{NEt}_{2}\right]$ was combined with 4,6bis(chloromethyl)dibenzothiophene, $\mathbf{5}$, in toluene at $0{ }^{\circ} \mathrm{C}$, and the mixture was heated and stirred at $85^{\circ} \mathrm{C}$ for $12 \mathrm{~h}$. Following workup, the crude product was crystallized from $\mathrm{MeOH}: \mathrm{CH}_{2} \mathrm{Cl}_{2}: \mathrm{Et}_{2} \mathrm{O}$ solution

[Insert Scheme 1 near here]

providing a quasi-diastereopure fraction of $R, S$ (meso) isomer (containing less than $3 \%$ of the $R, R$ and $S, S$ isomers $(\mathrm{rac})$ ) as colorless block-like crystals in $17 \%$ yield. The mother liquor from the crystallization was recovered, purified by column chromatography, and a diastereomeric mixture of isomers (meso/rac 29/71) was isolateded in $46 \%$ yield (global yield $63 \%$, meso/rac 47/53). Elemental analysis (CHN) for 2 is in good agreement with a monohydrate composition, $\mathbf{2} \cdot \mathrm{H}_{2} \mathrm{O}$, and a high resolution mass spectrum shows parent, $\left[\mathrm{M}+\mathrm{H}^{+}\right]$, and $\left[\mathrm{M}+\mathrm{Na}^{+}\right]$ions. Infrared spectra of samples of meso-2 and the mixture meso/rac 29/71 are essentially identical, and both display strong absorptions at 1630 and $1185 \mathrm{~cm}^{-1}$ that are tentatively assigned to $v_{\mathrm{CO}}$ and $v_{\mathrm{PO}}$, respectively, although the latter overlaps with another strong band centered at $1205 \mathrm{~cm}^{-1}$. These frequencies compare favorably with the corresponding frequencies for the related pyridine $\mathrm{N}$-oxide ligand, $\mathbf{I}, 1632$ and $1186 \mathrm{~cm}^{-1}$ and for its pyridine precursor, $\mathbf{I}_{\mathbf{N}}, 1634$ and 1190 $\mathrm{cm}^{-1}$ [41]. The ${ }^{31} \mathrm{P}$ NMR spectra for all samples of $\mathbf{2}$ are identical, and a single resonance appears at $\delta 30.2$ in $\mathrm{CDCl}_{3}\left(33.8\right.$ in $\left.d_{4}-\mathrm{MeOH}\right)$. This shift is identical to that for $\mathbf{I}_{\mathbf{N}}, \delta 30.4$, in $\mathrm{CDCl}_{3}$. It is noted that two 
resonances are resolved for the $\mathrm{N}$-oxide, $\mathbf{I},: \delta 32.5$ (rac) and 30.8 (meso) in $\mathrm{CDCl}_{3}[41]$. The ${ }^{1} \mathrm{H}$ and ${ }^{13} \mathrm{C}$ NMR spectra are consistent with the presence of the diastereomers, and the methine resonances in the CMPO fragment appear at $\delta 4.07, J_{\mathrm{HP}}=11.8 \mathrm{~Hz},($ rac and meso $)$ and $\delta 46.1, J_{\mathrm{CP}}=60.5(\mathrm{rac})$ and $\delta 46.2$, $J_{\mathrm{CP}}=61.2 \mathrm{~Hz}$ (meso), respectively. The ${ }^{1} \mathrm{H}$ and ${ }^{13} \mathrm{C}$ NMR data are comparable with data for $\mathbf{I}_{\mathrm{N}}: \delta 4.30$, $J_{\mathrm{HP}}=13.1 \mathrm{~Hz}(\mathrm{rac}), \delta 4.14, J_{\mathrm{HP}}=13.1 \mathrm{~Hz}($ meso $)$ and $\delta 46.0, J_{\mathrm{CP}}=62.0 \mathrm{~Hz}(\mathrm{rac})$ and $\delta 46.5, J_{\mathrm{CP}}=61.2$ $\mathrm{Hz}($ meso) [41].

The molecular structure of meso-2, co-crystallized with two molecules of $\mathrm{MeOH}$, was determined by single crystal X-ray diffraction analysis. A view of the molecule is shown in Figure 2, and selected bond lengths are summarized in Table 2. The DBT platform is planar and the $\mathrm{P}=\mathrm{O}$ and $\mathrm{C}=\mathrm{O}$ donor groups in the CMPO fragments are rotated away from each other in order to minimze dipole-dipole repulsions. The $\mathrm{P}=\mathrm{O}$ and $\mathrm{C}=\mathrm{O}$ bond lengths, $1.4958(16)$ and 1.4881(16) $\AA[1.492 \pm 0.004 \AA(\mathrm{avg})]$ and $1.229(3)$ and $1.227(3) \AA[1.228 \pm 0.001 \AA$ (avg)], respectively, are similar to the values in $\mathbf{H}, 1.481(2)$ and $1.218(4) \AA$ [41]. The lattice $\mathrm{MeOH}$ molecules are hydrogen bonded to the phosphoryl O-atoms with O5-H5 $0.84 \AA$,

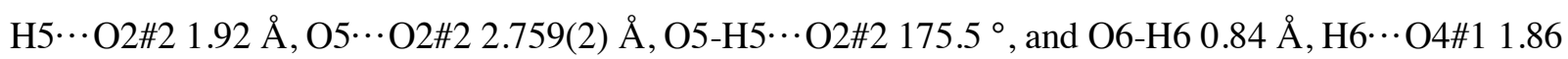

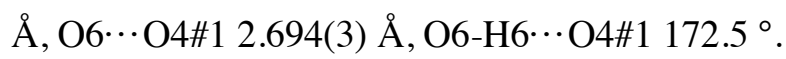

[Insert Figure 2 near here]

A racemic mixture of isomers of compound $\mathbf{3}$ was obtained in high yield by S-oxidation of a sample of 2 (meso/rac 29/71) with excess $m$ CPBA in $\mathrm{CH}_{2} \mathrm{Cl}_{2}$. Similarly, diastereopure 3 (meso) was obtained from oxidation of meso-2. Elemental analysis (CHN) for $\mathbf{3}$ is in good agreement with a dihydrate composition, 3. $\left(\mathrm{H}_{2} \mathrm{O}\right)_{2}$ and the HRMS displays $\left[\mathrm{M}+\mathrm{H}^{+}\right],\left[\mathrm{M}+\mathrm{Na}^{+}\right],\left[\mathrm{M}+\mathrm{K}^{+}\right]$and $\left[\mathrm{M}+\mathrm{H}+\mathrm{K}^{2+}\right]$ ions. Infrared spectra display two strong absorptions at 1635 and $1184 \mathrm{~cm}^{-1}$ that are assigned to $v_{\mathrm{CO}}$ and $v_{\mathrm{PO}}$, respectively. In addition, two strong absorptions appear at 1290 and $1155 \mathrm{~cm}^{-1}$ that are assigned to $v_{\mathrm{SO}(\mathrm{as})}$ and $v_{\mathrm{SO}(\mathrm{sym})}$, respectively. Contrary to the observations with $\mathbf{2}$, the ${ }^{31} \mathrm{P} \mathrm{NMR}$ spectrum for the diastereoisomeric mixture of $\mathbf{3}$ in $\mathrm{CDCl}_{3}$ shows two singlet resonances: $\delta 30.3$ (rac) and 30.7 (meso). In 
$\mathrm{MeOH}$ solution, the two peaks overlap with $\delta 34.0$. The methine proton resonance of the CMPO fragment, $\delta 4.54, J_{\mathrm{HP}}=11.7 \mathrm{~Hz}$ ( $r a c$ and meso), appears significantly downfield of the resonance for $\mathbf{2}$, while the ${ }^{13} \mathrm{C}$ resonance is slightly upfield: $\delta 45.7, J_{\mathrm{CP}}=59.3 \mathrm{~Hz}(\mathrm{rac})$ and $\delta 45.8, J_{\mathrm{CP}}=60.6 \mathrm{~Hz}$ (meso). Attempts to obtain X-ray diffraction quality single crystals of $\mathbf{3}$ were not successful.

\subsection{Molecular mechanics calculations}

The potential chelation interactions for ligands $\mathbf{2}$ and $\mathbf{3}$ were initially assessed with CPK model constructs, and these suggested that 2 might be expected to adopt a tetradentate $\mathrm{O}_{\mathrm{P}} \mathrm{O}_{\mathrm{C}} \mathrm{O}_{\mathrm{P}} \mathrm{O}_{\mathrm{C}}$ interaction on a $\mathrm{Ln}(\mathrm{III})$ ion while 3 might bind in a pentadentate $\mathrm{O}_{\mathrm{P}} \mathrm{O}_{\mathrm{C}} \mathrm{O}_{\mathrm{S}} \mathrm{O}_{\mathrm{P}} \mathrm{O}_{\mathrm{C}}$ mode. With 2 , it appeared that the thiophene S-atom would be geometrically too far removed from a central $\mathrm{Ln}$ (III) ion in a hypothetical $[\operatorname{Ln}(2)]^{3+}$ species for a significant interaction. Furthermore, the soft thiophene S-atom would be expected to act as a very weak donor toward $\operatorname{Ln}(\mathrm{III})$ ions. As described in several recent reports [34-36,41], ligand strain free energies for 1:1 $\mathrm{Ln}(\mathrm{III}) /$ ligand complexes, obtained from molecular mechanics (MM) calculations, have been successfully used to more quantitatively assess potential chelate binding conditions; therefore, these calculations were performed for both ligands. For $R, S-2^{*}$, the computed, energy minimized free ligand geometry is shown in Figure 3a. It is noted that $2 *$ differs from 2 only by replacement of the $\mathrm{NEt}_{2}$ substituent groups in 2 by $\mathrm{NMe}_{2}$ in $2 *$ which was done for computational expediency. The computed gas phase resting state structure is similar to that found from the crystal structure determination in that the donor groups are rotated away from each other. However, the structures differ slightly due to hydrogen bonding of the phosphine oxide $\mathrm{O}$-atoms with lattice $\mathrm{MeOH}$ and crystal packing forces in the experimental solid state. The evaluation of the strain free energy $(G)$ for an energy minimized tetradentate $\mathrm{O}_{\mathrm{P}} \mathrm{O}_{\mathrm{C}} \mathrm{O}_{\mathrm{P}} \mathrm{O}_{\mathrm{C}}$ interaction in $[\mathrm{Eu}(R, S-2 *)]^{3+}$, shown in Figure $3 \mathrm{~b}$, results in $G$ $=19.36 \mathrm{kcal} / \mathrm{mole}$ or $4.84 \mathrm{kcal} / \mathrm{mole} /$ donor group. This strain energy is significantly greater than the strain energy computed for a bidentate $\mathrm{O}_{\mathrm{P}} \mathrm{O}_{\mathrm{P}}$ complex containing the related DBT ligand $\mathbf{D},[\mathrm{Eu}(\mathbf{D})]^{3+}, \mathrm{G}$ $=2.94 \mathrm{kcal} / \mathrm{mole}$ or $1.47 \mathrm{kcal} /$ mole/donor [35]. This comparison suggests that, based upon ligand strain energy alone, a bidentate $\mathrm{O}_{\mathrm{P}} \mathrm{O}_{\mathrm{P}}$ binding mode might also be preferred by $\mathbf{2}$. Of course the greater steric 
strain encountered in a tetradentate $\mathrm{O}_{\mathrm{P}} \mathrm{O}_{\mathrm{C}} \mathrm{O}_{\mathrm{P}} \mathrm{O}_{\mathrm{C}}$ interaction may be overcome by the additional lanthanideamide bond formation. Attempts to model a pentadentate $\mathrm{O}_{\mathrm{P}} \mathrm{O}_{\mathrm{C}} \mathrm{SO}_{\mathrm{P}} \mathrm{O}_{\mathrm{C}}$ structure confirms that the $\mathrm{S}$-atom does not approach the Eu(III) ion at a reasonable bond length $(\mathrm{Eu} \cdots \mathrm{S}>3.5 \AA$ ). The strain free energy in a tetradentate structure of $\left[\mathrm{Eu}\left(R, R-2^{*}\right)\right]^{3+}, \mathrm{G}=15.32 \mathrm{kcal} / \mathrm{mole}$, is slightly lower than that for $\left[\mathrm{Eu}\left(R, S-2^{*}\right)\right]^{3+}$

[Insert Figure 3 near here]

The structure for the sulfone ligand bonded in a pentadentate $\mathrm{O}_{\mathrm{P}} \mathrm{O}_{\mathrm{C}} \mathrm{O}_{\mathrm{S}} \mathrm{O}_{\mathrm{P}} \mathrm{O}_{\mathrm{C}}$ mode in $\left[\mathrm{Eu}\left(R, S-3^{*}\right)\right]^{3+}$, as shown in Figure 4a, generates a computed strain free energy $G=20.29 \mathrm{kcal} /$ donor group or 4.06 $\mathrm{kcal} / \mathrm{mole} /$ donor group. The strain energy encountered in adoption of a tridentate $\mathrm{O}_{\mathrm{P}} \mathrm{O}_{\mathrm{S}} \mathrm{O}_{\mathrm{P}}$ structure in $\left[\mathrm{Eu}\left(R, \mathrm{~S}^{-3^{*}}\right)\right]^{3+}$, as shown in Figure $4 \mathrm{~b}$, is much lower, $\mathrm{G}=7.23 \mathrm{kcal} / \mathrm{mole}$ or $2.41 \mathrm{kcal} / \mathrm{mole} /$ donor, although this value is significantly greater than the strain energy developed for a tridentate $\mathrm{O}_{\mathrm{P}} \mathrm{O}_{\mathrm{S}} \mathrm{O}_{\mathrm{P}}$ chelate structure in $[\mathrm{Eu}(\mathbf{E})]^{3+}: \mathrm{G}=2.73 \mathrm{kcal} / \mathrm{mole}$ or $0.91 \mathrm{kcal} / \mathrm{mole} /$ donor group. The strain free energy for the pentadentate coordination mode in $\left[\mathrm{Eu}\left(R, R-3^{*}\right)\right]^{3+}$ is $\mathrm{G}=18.90 \mathrm{kcal} / \mathrm{mole}$ or $3.78 \mathrm{kcal} / \mathrm{mole} /$ donor group. Taken together it appears that the addition of the amide functionality to the D- and $\mathbf{E}$-type ligand frameworks results in significant increases in ligand strain energy when maximal chelate binding conditions are adopted, and this would be expected to impact the stabilities and structures of complexes in solutions and in the solid state.

[Insert Figure 4 near here]

\subsection{Synthesis and characterization of lanthanide coordination complexes}

The coordination chemistry of 2 and $\mathbf{3}$ with $\mathrm{Ln}\left(\mathrm{NO}_{3}\right)_{3} \times \mathrm{x}\left(\mathrm{H}_{2} \mathrm{O}\right)(\mathrm{Ln}=\mathrm{La}, \mathrm{Pr}, \mathrm{Eu}, \mathrm{Er}, \mathrm{Lu})$ salts was examined by using a 1:1 L:Ln combining ratio in $\mathrm{MeOH}$ or $\mathrm{MeOH} / \mathrm{EtOAc}$ solutions. The resulting complexes were isolated as powders. The $\mathrm{CHN}$ elemental analysis data are most consistent with the 


\subsection{X-ray crystal structure determination for a lanthanide complex}

Since the binding modes for ligands $\mathbf{2}$ and $\mathbf{3}$ in their respective 1:1 $\mathrm{Ln}(\mathrm{III})$ coordination complexes could not be confidently assigned based upon infrared spectra alone, attempts were made to grow single crystals of representative complexes for X-ray crystal structure determinations. Considerable difficulty was encountered in the efforts to obtain diffraction quality crystals due in part to facile loss of lattice 
solvent during sample handling and crystal mounting. However, in one case, the slow (5 weeks) evaporation of a solution of the nominal complex $\left[\mathrm{Eu}(2)\left(\mathrm{NO}_{3}\right)_{3}\right]$, dissolved in a mixture of $\mathrm{MeOH}$ and $i$ PrOH (2:1), provided suitable single crystals for which a structure determination was accomplished. A view of the structure is shown in Figure 5, and selected bond lengths are listed in Table 2. It is immediately apparent that, in the crystal growth process, performed with exposure of the solution of $\left[\mathrm{Eu}(2)\left(\mathrm{NO}_{3}\right)_{3}\right]$ to air, the ligand 2 slowly undergoes partial oxidation to form the sulfoxide derivative, 4,6bis[(diphenyl-N,N-diethylcarbamoylmethylphosphine oxide)methyl]dibenzothiophene 5-oxide, 4. A complex of composition $\left[\mathrm{Eu}(4)\left(\mathrm{NO}_{3}\right)_{3}\right]$ is formed as schematically illustrated in Scheme 2. Disordered solvent molecules are also present in the outer coordination sphere that could not be successfully modeled, and they were accounted for by application of the SQUEEZE procedure. The nine coordinate $\mathrm{Eu}(\mathrm{III})$ ion is bonded to the potentially pentadentate ligand in a tridentate $\mathrm{O}_{\mathrm{P}} \mathrm{O}_{\mathrm{S}} \mathrm{O}_{\mathrm{P}}$ mode with the two amide carbonyl groups rotated away from the inner coordination sphere. The Eu- $\mathrm{O}_{\mathrm{P}}$ bond lengths, Eu1O4 2.299(3) $\AA$ and Eu1-O2 2.321(3) $\AA$ are similar to the Eu-O $\mathrm{P}_{\mathrm{P}}$ bond lengths in the 1:1 tridentate NOPOPO complex $\left[\mathrm{Eu}(\mathbf{F})\left(\mathrm{NO}_{3}\right)_{3}\right]\left(\mathrm{R}=2-\mathrm{CF}_{3} \mathrm{C}_{6} \mathrm{H}_{4}\right), 2.334(2)$ and 2.320(2) $\AA$ [36] and shorter than the Eu-O $\mathrm{O}_{\mathrm{P}}$ distances in $\left\{\left[\mathrm{Eu}(\mathbf{E}) \mathrm{Cl}_{3}\right]_{2}(\mu-\mathbf{E})\right\}(\mathrm{R}=\mathrm{Ph}), 2.358(3)$ and 2.360(3) $\AA$ [35]. The Eu-O $\mathrm{O}_{\mathrm{S}}$ bond length, 2.491(3) $\AA$, is slightly longer than the Eu- $\mathrm{O}_{\mathrm{N}}$ bond length, 2.424(2) $\AA$ in $\left[\mathrm{Eu}(\mathbf{F})\left(\mathrm{NO}_{3}\right)_{3}\right][36]$, and it is much shorter than the Eu-O $\mathrm{O}_{\mathrm{S}}$ bond length in the complex $\left\{\left[\mathrm{Eu}(\mathbf{E}) \mathrm{Cl}_{3}\right]_{2}(\mu-\mathbf{E})\right\}, 2.572(3) \AA$ [35]. There are also six O-atoms from three asymmetrically bonded nitrate anions in the inner coordination sphere. The geometry of the sulfone S-atom is distorted pyramidal with bond angles C11-S1-C12 90.3(2) ${ }^{\circ}$, C11-S1$\mathrm{O} 5110.3(2)^{\circ}$ and C12-S1-O5 $109.3(2)^{\circ}$, and the O-atom geometry is bent with a bond angle S1-O5-Eu1 $136.3(2)^{\circ}$

[Insert Figure 5 near here]

Given the results of the crystal structure determination, attempts were made to confirm the composition of $\left[\mathrm{Eu}(4)\left(\mathrm{NO}_{3}\right)_{3}\right]$ by HRMS analysis under a variety of sample injection and ionization potential conditions. In no case was the parent ion detected; however, an ion corresponding to $\left[\mathbf{4}+\mathrm{H}^{+}\right]$ 
was observed. In addition, an IR spectrum of the complex shows a strong $v_{\mathrm{CO}}$ absorption at $1635 \mathrm{~cm}^{-1}$ compared to the value of $1601 \mathrm{~cm}^{-1}$ recorded for the initially formed complex, $\left[\mathrm{Eu}(2)\left(\mathrm{NO}_{3}\right)_{3}\right]$. The observed absorption more closely compares with the carbonyl stretching frequency in the free ligand $\mathbf{2}$, and this is consistent with the observation in the crystal structure that the amide carbonyl groups are not involved in $\mathrm{Eu}(\mathrm{III})$ coordination. There is also a new absorption at $973 \mathrm{~cm}^{-1}$ that is tentatively assigned to a coordinated $v_{\text {So }}$ mode. Similarly, $\left[\mathrm{Lu}(2)\left(\mathrm{NO}_{3}\right)_{3}\right]$ also undergoes slow ligand oxidation in air at room temperature with formation of $\left[\mathrm{Lu}(4)\left(\mathrm{NO}_{3}\right)_{3}\right]$, and the complex displays IR absorptions at 1632, 1157 and $975 \mathrm{~cm}^{-1}$ that are assigned to $v_{\mathrm{CO}}, v_{\mathrm{PO}}$ and $v_{\mathrm{SO}}$ modes, respectively. It is worthwhile to mention that attempts were made to prepare $\mathbf{4}$ via controlled air oxidation of $\mathbf{2}$, and the ligand $\mathbf{2}$ appears to be stable under the synthetic conditions examined. Thus, this suggests that the $\operatorname{Ln}(\mathrm{III})$ ion may play a role to catalyze the S-oxidation reaction. This observation is interesting and worthy of additional study since there continues to be interest in new methods for mild oxidative conversion of DBT and its derivatives present in diesel fuel feedstocks followed by extraction of the resulting sulfone [54-56].

\subsection{Solvent extraction analysis}

The solvent extraction performances of diastereomeric mixtures (meso/rac 29/71) of 2 and $\mathbf{3}$, dissolved in 1,2-dichloroethane (1,2-DCE, $0.01 \mathrm{M})$, toward Eu(III) and Am (III) in nitric acid solutions were surveyed, and the variations in distribution ratios $\left(\mathrm{D}=\left[\mathrm{M}_{\mathrm{org}}\right] /\left[\mathrm{M}_{\mathrm{aq}}\right]\right)$, as a function of $\left[\mathrm{HNO}_{3}\right]$, are displayed in Figure 6 along with distribution ratios for the structurally related pyridine N-oxide ligand, I [41] and the well-known CMPO extractant (n-octyl)(phenyl)-N,N-diisobutylcarbamoylmethylphosphine oxide, $\mathrm{OPhDiBCMPO}, \mathbf{G}\left(\mathrm{R}=\mathrm{Ph}, \mathrm{R}^{\prime}=n\right.$-octyl, $\mathrm{R} "=i$ - $\left.\mathrm{Bu}\right)$ [57]. Each of these ligands displays increasing D values with increasing acid strength at least up to $1 \mathrm{M}\left[\mathrm{HNO}_{3}\right]$. In the case of $\mathbf{G}$, the $\mathrm{D}$ values then begin to decrease with increasing acid concentration above $1 \mathrm{M}\left[\mathrm{HNO}_{3}\right]$ due most likely to competitive proton binding with the ligand. For 2,3 and $\mathbf{I}$, the $\mathrm{D}$ values continue to increase up to $3 \mathrm{M}$ acid concentration. In addition, $\mathbf{2}, \mathbf{3}$ and $\mathbf{I}$ show much larger D values than the CMPO ligand $\mathbf{G}$ at all acid strengths. It is also apparent that the variations in D values for $\mathbf{2 , 3}$ and $\mathbf{I}$ are very similar suggesting that 
the DBT and pyridine N-oxide platform donor groups may not be strongly influencing the extraction thermodynamics beyond serving to assemble the two CMPO fragments in a favorable geometric condition suitable for effective metal ion binding in DCE solution. It is also pointed out that $\mathbf{2 , 3}$ and $\mathbf{I}$ are superior extractants compared to the bis-(methylphosphine oxide) compounds C-E [34,35]. Extractions with samples of meso-2 and meso-3 were also performed, and the plots $\mathrm{D}$ vs $\left[\mathrm{HNO}_{3}\right]$ are provided in the Supplementary Data. The D values are slightly smaller than those measured for the meso/rac (29/71) mixtures indicating that the rac isomers $(R, R S, S)$ are slightly better extractants than the meso form.

\subsection{Conclusion}

A straight forward synthesis for the hybrid DBT/CMPO ligand 2 that unites the DBT platform with two CMPO fragments has been developed, and the molecule has been characterized by spectroscopic methods. The compound is stable toward air oxidation, but it undergoes efficient S-oxidation by $m$ CBPA in $\mathrm{CH}_{2} \mathrm{Cl}_{2}$ solution at room temperature with formation of the sulfone derivative 3 . No evidence for the formation of an intermediate sulfoxide is observed in solution or the solid state. The coordination chemistry of $\mathbf{2}$ and 3 with $\mathrm{Ln}\left(\mathrm{NO}_{3}\right)_{3}$ salts was explored, and solid, 1:1 complexes, $\left[\mathrm{Ln}(\mathbf{2})\left(\mathrm{NO}_{3}\right)_{3}\right]$ and $\left[\mathrm{Ln}(3)\left(\mathrm{NO}_{3}\right)_{3}\right]$, with varying degrees of undefined outer coordination sphere solvation, were isolated and examined by IR spectroscopy. Coordination shifts for the $\left[\mathrm{Ln}(\mathbf{2})\left(\mathrm{NO}_{3}\right)_{3}\right]$ complexes suggest that 2 may bind in a tetradentate $\mathrm{O}_{\mathrm{P}} \mathrm{O}_{\mathrm{C}} \mathrm{O}_{\mathrm{P}} \mathrm{O}_{\mathrm{C}}$ fashion by using the two appended CMPO fragments on the DBT platform. The absence of DBT S-atom participation in forming the coordination complex is consistent with ligand strain energetics assessed by molecular mechanics calculations although those calculations suggest lower strain energy for the formation of a bidentate $\mathrm{O}_{\mathrm{P}} \mathrm{O}_{\mathrm{P}}$ coordination mode as opposed to the tetradentate structure. The presence of a shoulder on the infrared band assigned to $v_{\mathrm{CO}}$ in the complex may indicate that one of the two carbonyl groups is not directly bound or is weakly bound to the $\operatorname{Ln}(\mathrm{III})$ ion in the solid state. The infrared spectra for the nominal $\left[\mathrm{Ln}(3)\left(\mathrm{NO}_{3}\right)_{3}\right.$ complexes appear to support a structure that involves the amide carbonyl group in ligand binding to the $\operatorname{Ln}(\mathrm{III})$ ion. Furthermore, the $v_{\mathrm{PO}}$ stretch of the free ligand disappears in the spectra of the complexes consistent with phosphine oxide coordination; 
however, band overlaps in the region expected for a coordinated phosphine oxide stretching absorption discourage definitive conclusions regarding the involvement of the $\mathrm{P}=\mathrm{O}$ groups in a chelate interaction. These spectra also seem to indicate no direct involvement of the sulfone O-atoms in the ligand binding. Unfortunately, single crystal X-ray structure analyses for $\left[\mathrm{Ln}(\mathbf{2})\left(\mathrm{NO}_{3}\right)_{3}\right]$ and $\left[\mathrm{Ln}(\mathbf{3})\left(\mathrm{NO}_{3}\right)_{3}\right]$ complexes that would conclusively identify the spectroscopically consistent tetradentate $\mathrm{O}_{\mathrm{P}} \mathrm{O}_{\mathrm{C}} \mathrm{O}_{\mathrm{P}} \mathrm{O}_{\mathrm{C}}$ or computationally suggested tridentate $\mathrm{O}_{\mathrm{P}} \mathrm{O}_{\mathrm{S}} \mathrm{O}_{\mathrm{P}}$ bonding modes, respectively, were not accomplished. It is noted, by comparison, that X-ray crystal structure determinations for 2:1 CMPO/Ln(III) complexes show that both CMPO ligands adopt a bidentate $\mathrm{O}_{\mathrm{P}} \mathrm{O}_{\mathrm{C}}$ binding mode on early $\mathrm{Ln}$ (III) ions, but in post-Gd(III) complexes, the carbonyl O-atoms are not bound to the smaller $\mathrm{Ln}(\mathrm{III})$ ions. Instead, they hydrogen bond with inner sphere solvent molecules $[58,59]$. It is also very interesting that $\mathbf{2}$, which is very stable toward air oxidation in its metal-free state, undergoes partial S-oxidation in air when coordinated with Ln(III) ions. Further, the X-ray structure determination for the unexpected sulfoxide complex, $\left[\mathrm{Eu}(4)\left(\mathrm{NO}_{3}\right)_{3}\right]$, provides the computationally predicted structural result wherein 4 binds with $\mathrm{Eu}(\mathrm{III})$ in a tridentate $\mathrm{O}_{\mathrm{P}} \mathrm{O}_{\mathrm{S}} \mathrm{O}_{\mathrm{P}}$ manner. Lastly, the favorable extraction performance of $\mathbf{2}$ and $\mathbf{3}$ encourage the additional development of DBT/CMPO hybrid ligand analogs of $\mathbf{H}$, and that work and additional studies of $\mathbf{4}$ are in progress.

\section{Acknowledgements}

This material is based upon work supported by the U.S. Department of Energy (DoE), Office of Science, Office of Basic Energy Sciences, Chemical Sciences, Geosciences and Biosciences Office, under Award Number DE-FG02-03ER15419) (RTP). In addition, funds from the National Science Foundation assisted the purchase of the X-ray diffractometer (CHE-0443580) and NMR spectrometers (CHE0840523 and 0946690). 


\section{References}

[1] R. D. Hancock, A. E. Martell, Chem. Rev. 89 (1989) 1875.

[2] B. P. Hay, D. Zhang, J. R. Rustad, Inorg. Chem. 35 (1996) 2650.

[3] H. -J. Schneider, A. Yatsimirski, Principles and Methods in Supramolecular Chemistry, J.Wiley, New York, 2000.

[4] B. P. Hay, R. D. Hancock, Coord. Chem. Rev. 212, (2001) 61.

[5] J. W. Steed, J. L. Atwood, Supramolecular Chemistry, $2^{\text {nd }}$ Ed., J. Wiley, New York, 2007.

[6] B. P. Hay, C. Jia, J. Nadas, Comput.Theoret. Chem. 1028 (2014) 72.

[7] M. W. Haenel, D. Jakubik, E. Rothenberger, G. Schroth, Chem. Ber. 124 (1991) 1705.

[8] M. Kranenburg, Y. E. M. van der Burgt, P. C. J. Kamer, P. W. N. M. van Leeumen, K. Govbitz, J. Fraamje, Organometallics 14 (1995) 3081.

[9] E. M. Vogl, J. Bruckmann, C. Krüger, M. W. Haenel, J. Organomet. Chem. 520 (1996) 249.

[10] E. M. Vogl, J. Bruckmann, M. Kessler, C. Krüger, M. W. Haenel, Chem. Ber. 130 (1997) 1315.

[11] M. L. Hlavinka, J. R. Hagadorn, Chem. Commun. (2003) 2686.

[12] M. L. Skar, J. S. Svendsen, Tetrahedron 53 (1997) 17425.

[13] S. Kanemasa, Y. Oderaotoshi, H. Yamamoto, J. Tanaka, E. Wada, J. Org. Chem. 62 (1997) 6454.

[14] S. Kanemasa, Y. Oderaotoshi, S. Sakaguchi, H. Yamamoto, J. Tanaka, E. Wada, D. P. Curran, J. Am. Chem. Soc. 120, (1998) 3074.

[15] Y. Deng, C. J. Chang, D. G. Nocera, J. Am. Chem. Soc. 122 (2000) 410.

[16] R. Kaul, S. Deechongkit, J. W. Kelly, J. Am. Chem. Soc. 124 (2002) 11900.

[17] S. -M. Kuang, P. E. Fanwick, R. A. Walton, Inorg. Chem. 41 (2002) 405. 
[18] P. L. Caradoc-Davies, L. R. Hanton, Dalton Trans. (2003) 1754.

[19] A. Pintado-Alba, H. de la Riva, M. Nieuwhuyzen, D. Bautista, P. R. Raithby, H. A. Sparks, S. J.

Teat, J. M. López-de-Luzuriaga, C. M. Lagunas, Dalton Trans. (2004) 3459.

[20] R. M. Porter, A. A. Danopoulos, Polyhedron 25 (2006) 859.

[21] H. de-la-Riva, M. Nieuwhuyzen, C. M. Fierro, P. R. Raithby, L. Male, M. C. Lagunas, Inorg. Chem. 45 (2006) 1418.

[22] C. Han, G. Xie, J. Li, Z. Zhang, H. Xu, Z. Dend, Y. Zhao, P. Yan, S. Liu, Chem. Eur. J. 17 (2011)

8947.

[23] T. A. Robbins, D. J. Cram, J. Chem. Soc. Chem. Commun. (1995) 1515.

[24] K. Agbaria, S. E. Biali, J. Org. Chem. 66, (2001) 5482.

[25] F. Li, R. Delgado, M. G. B. Drew, V. Félix, Dalton Trans. (2006) 5396.

[26] F. Li, 1. Li, R. Delgado, M. G. B. Drew, V. Félix, Dalton Trans. (2007) 1316.

[27] H. H. Dam, D. N. Reinhoudt, W. Verboom, Chem. Soc. Rev. 36 (2007) 367.

[28] Z. Kolaric, Chem. Rev. 108 (2008) 4208.

[29] B. J. Mincher, G. Modolo, S. P. Mezyk, Solvent Extr. Ion Exch. 28 (2010) 415.

[30] F. W. Lewis, M. J. Hudson, L. M. Harwood, Syn. Lett. 18 (2011) 2609.

[31] P. J. Panak, A. Geist, Chem. Rev. 113 (2013) 1199.

[32] F. W. Lewis, L. M. Harwood, M. J. Hudson, M. G. B. Drew, V. Hubscher-Bruder, V. Videva, F. Arnaud-Neu, K. Stamberg, S. Vyas, Inorg. Chem. 52 (2013) 4993.

[33] M. J. Hudson, L. M. Harwood, D. M. Laventine, F. W. Lewis, Inorg. Chem. 52 (2013) 3414. 
[34] D. Rosario-Amorin, E. N. Duesler, R. T. Paine, B. P. Hay, L. H. Delmau, S. D. Reilly, A. J. Gaunt, B. L. Scott, Inorg. Chem. 51 (2012) 6667.

[35] D. Rosario-Amorin, S. Ouizem, D. A. Dickie, R. T. Paine, R. E. Cramer, B. P. Hay, J. Podair, L. H. Delmau, Inorg. Chem. 53 (2014) 5698.

[36] S. Pailloux, C.E. Shirima, A.D. Ray, E.N. Duesler, R.T. Paine, J.R. Klaehn, M.E. McIlwain, B.P. Hay, Inorg. Chem. 48 (2009) 3104 and references therein.

[37] J. Sulakova, R. T. Paine, M. Chakravarty, K.L. Nash, Sep. Sci. Tech. 47 (2012) 2015 and references therein.

[38] E.P. Horwitz, W.W. Schulz, ACS Symp. Ser. 716 (1999) 20, and references therein.

[39] A.M. Rozen, B. V. Krupnov, Russ. Chem. Rev. 65 (1996) 973 and references therein.

[40] E. V. Sharova, O. I. Artyushin, I. L. Odinets, Russ. Chem. Rev. 83 (2014) 95.

[41] D. Rosario-Amorin, S. Ouizem, D.A. Dickie, Y. Wen, R. T. Paine, J. Gao, J. K. Grey, A, de Bettencourt Dias, B. P. Hay, L.H. Delmau, Inorg. Chem. 52 (2013) 3063.

[42] S.Ouizem, D. Rosario-Amorin, D. A. Dickie, R. T. Paine, A. deBettencourt-Dias, B. P. Hay, J. Podair, L. H. Delmau, Dalton Trans. 43 (2014) 8368.

[43] SAINT + 7.01, (2003) Bruker AXS, Inc., Madison, WI 53719.

[44] APEX 2, (2007); Bruker AXS, Inc.: Madison, WI,53719.

[45] G.M. Sheldrick, SADABS 2.10, (2003), University of Gottingen: Gottingen, Germany.

[46] SHELXL-97, (2008), Bruker AXS, Inc.: Madison, WI 53719.

[47] P. van der Sluis, A.L. Spek, Acta Crystallogr. A46 (1990) 194.

[48] A.L. Spek, Acta Crystallogr. A46 (1990) C34. 
[49] N.L. Allinger, Y.-H. Yuh, J.-H. Lii, J. Am. Chem. Soc. 111 (1989) 8551.

[50] J.-H. Lii, N.L. Allinger, J. Am. Chem. Soc. 111 (1989) 8566.

[51] J.-H. Lii, N.L. Allinger, J. Am. Chem. Soc. 111, (1989) 8576.

[52] B.P. Hay, Coord. Chem. Rev. 126 (1993) 177.

[53] PCModel, version 9.3, Serena Software, Bloomington, IN.

[54] V. C. Srivastava, RSC Adv. 2 (2012) 759 and references therein.

[55] N. Tang, Y. Zhang, F. Lin, H. Lü, Z. Jiang, C. Li, Chem. Commun. 48 (2012) 11647 and references therein.

[56] H. Lü, P. Li, C. Deng, W. Ren, S. Wang, P. Liu, H. Zhang, Chem. Commun. 51 (2015) 10703 and references therein.

[57] E.P. Horwitz, D.G. Kalina, H. Diamond, G.F. Vandegrift, W.W. Schulz, Solvent Extr. Ion Exch. 3 (1985) 75 .

[58] S.M. Bowen, E. N. Duesler, R.T. Paine, Inorg. Chim. Acta 61 (1982) 155.

[59] L.J. Caudle, E.N. Duesler, R.T. Paine, Inorg. Chem. 24 (1985) 4441. 
Table 1. Crystallographic Data for meso-2 $2 \mathrm{MeOH}$ and $\left[\mathrm{Eu}(4)\left(\mathrm{NO}_{3}\right)_{3}\right]$

\begin{tabular}{|c|c|c|}
\hline & meso-2.2MeOH & {$\left[\mathrm{Eu}(\mathbf{4})\left(\mathrm{NO}_{3}\right)_{3}\right]$} \\
\hline Empirical formula & $\mathrm{C}_{52} \mathrm{H}_{60} \mathrm{~N}_{2} \mathrm{O}_{6} \mathrm{P}_{2} \mathrm{~S}$ & $\mathrm{C}_{50} \mathrm{H}_{52} \mathrm{EuN}_{5} \mathrm{O}_{14} \mathrm{P}_{2} \mathrm{~S}$ \\
\hline Crystal size (mm) & $\begin{array}{c}0.220 \times 0.320 \times \\
0.420\end{array}$ & $\begin{array}{c}0.061 \times 0.101 \times \\
0.280\end{array}$ \\
\hline Formula weight & 903.02 & 1192.92 \\
\hline Crystal system & triclinic & triclinic \\
\hline Space group & $P-1$ & $P-1$ \\
\hline Unit cell dimensions & & \\
\hline$a(\AA)$ & $9.3916(6)$ & 11.5741(4) \\
\hline$b(\AA)$ & $13.5785(9)$ & $15.5620(6)$ \\
\hline$c(\AA)$ & $20.9347(13)$ & $16.6012(6)$ \\
\hline$\alpha\left(^{\circ}\right)$ & 74.464(3) & $64.188(2)$ \\
\hline$\beta\left(^{\circ}\right)$ & $84.897(3)$ & $80.938(2)$ \\
\hline$\gamma\left({ }^{\circ}\right)$ & $70.158(3)$ & $84.805(2)$ \\
\hline $\mathrm{V}\left(\AA^{3}\right)$ & $2420.8(3)$ & $2657.40(17)$ \\
\hline $\bar{Z}$ & 2 & 2 \\
\hline $\mathrm{T},(\mathrm{K})$ & $173(2)$ & $100(2)$ \\
\hline
\end{tabular}




\begin{tabular}{|l|c|c|}
\hline $\mathrm{D}_{\text {cald }}\left(\mathrm{g} \mathrm{cm}^{-3}\right)$ & 1.240 & 1.491 \\
\hline$\mu\left(\mathrm{mm}^{-1}\right)$ & 0.184 & 1.348 \\
\hline Min/Max transmission & $0.9280 / 0.9610$ & $0.7040 / 0.9220$ \\
\hline Reflection collected & 29835 & 44429 \\
\hline Independent & & \\
reflections [R $\left.\mathrm{R}_{\text {int }}\right]$ & & $10491[0.0569]$ \\
\hline Final R indices [I $>2 \sigma$ & $0.0497(0.1335)$ & $0.0413(0.0959)$ \\
(I)]R1 ${ }^{\mathrm{a}}(w \mathrm{R} 2)^{\mathrm{b}}$ & & \\
\hline Final R indices (all & $0.0665(0.1457)$ & $0.0564(0.1027)$ \\
data) R1 $(w \mathrm{R} 2)$ & & \\
\hline
\end{tabular}

$$
{ }^{\mathrm{a}} \mathrm{R} 1=\left(\Sigma|| \mathrm{F}_{\mathrm{o}}|-| \mathrm{F}_{\mathrm{c}} \|\right) / \Sigma \mid \mathrm{F}_{\mathrm{o}} \mathrm{I} \cdot{ }^{\mathrm{b}} w \mathrm{R} 2=\left[\Sigma w\left(\mathrm{~F}_{\mathrm{o}}{ }^{2}-\mathrm{F}_{\mathrm{c}}{ }^{2}\right)^{2} / \Sigma \mathrm{W}\left(\mathrm{F}_{\mathrm{o}}{ }^{2}\right)^{2}\right]^{1 / 2} .
$$


Table 2. Selected Bond Lengths $(\AA)$ for 2 and $\left[\mathrm{Eu}(\mathbf{4})\left(\mathrm{NO}_{3}\right)_{3}\right]$

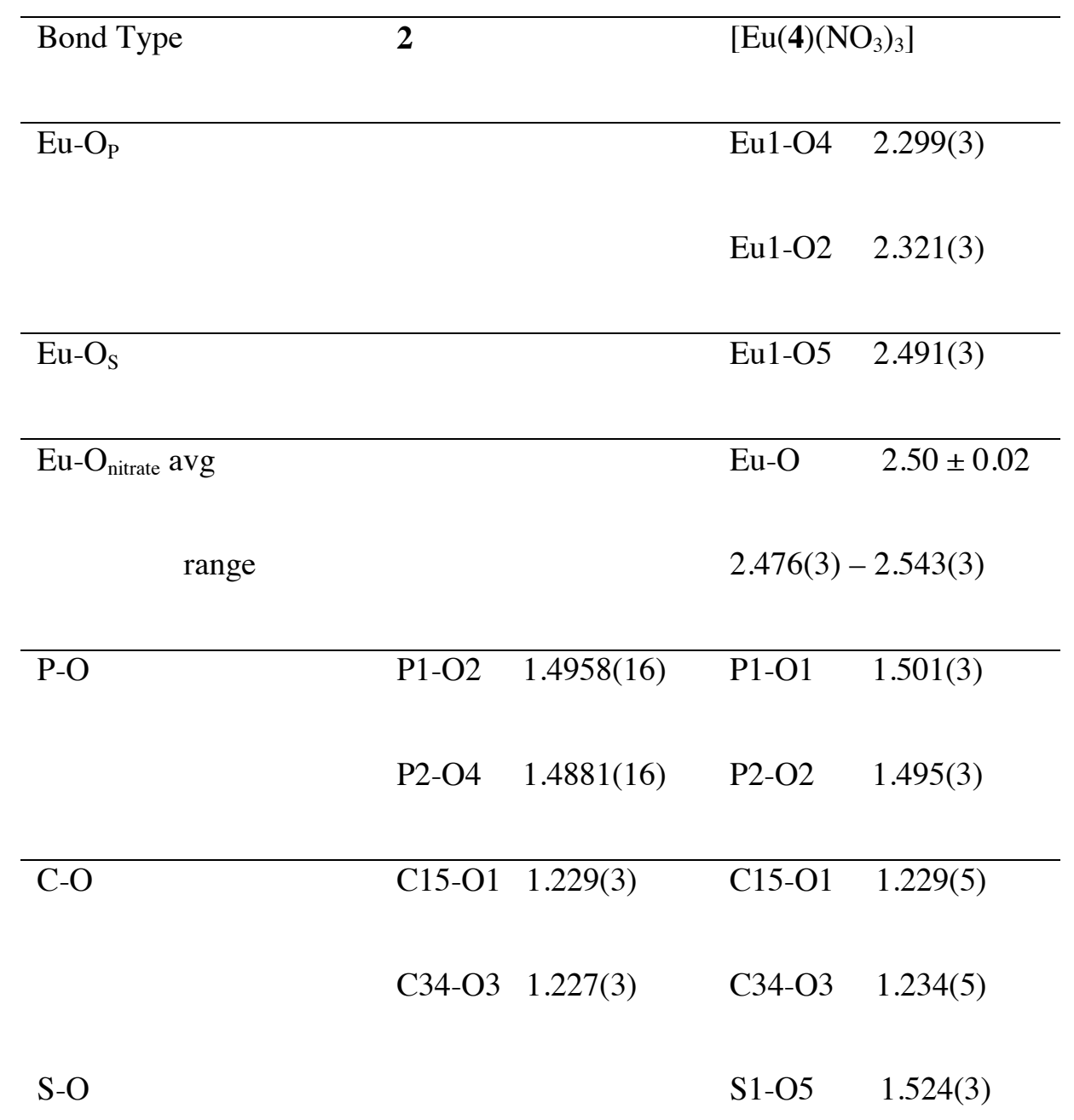


Figure Captions (in order that they appear)

Figure 1. Hybrid chelating ligand platform types, A-I.

Scheme 1. Synthesis of compounds 2 and $\mathbf{3}$.

Figure 2. Molecular structure and atom labeling scheme for meso-2.2MeOH with $\mathrm{H}$-atoms omitted except on the hydrogen bonded hydroxyl group of the methanol molecules. Thermal ellipsoids are shown at the $50 \%$ level.

Figure 3. Geometry optimized gas phase structures for a) $R, S-2^{*}$ and b) a $1: 1$ tetradentate $\mathrm{O}_{\mathrm{P}} \mathrm{O}_{\mathrm{C}} \mathrm{O}_{\mathrm{P}} \mathrm{O}_{\mathrm{C}}$ complex $[\mathrm{Eu}(R, S-2 *)]^{3+}$. Ligand $2 *$ contains $\mathrm{NMe}_{2}$ substituents in contrast to $\mathrm{NEt}_{2}$ substituents in $\mathbf{2}$, and the $\mathrm{H}$-atoms have been omitted from the views to improve clarity.

Figure 4. Geometry optimized gas phase structures for a) a $1: 1$ pentadentate $\mathrm{O}_{\mathrm{P}} \mathrm{O}_{\mathrm{C}} \mathrm{O}_{\mathrm{S}} \mathrm{O}_{\mathrm{P}} \mathrm{O}_{\mathrm{C}}$ complex $\left[\mathrm{Eu}\left(R, S-3^{*}\right)\right]^{3+}$ and b) a $1: 1$ tridentate $\mathrm{O}_{\mathrm{P}} \mathrm{O}_{\mathrm{S}} \mathrm{O}_{\mathrm{P}}$ complex $\left[\mathrm{Eu}\left(R, S-3^{*}\right)\right]^{3+}$. Ligand $\mathbf{3}^{*}$ contains $\mathrm{NMe}_{2}$ substituents in contrast to $\mathrm{NEt}_{2}$ substituents in $\mathbf{3}$, and the $\mathrm{H}$-atoms have been omitted from the views to improve clarity.

Scheme 2. Synthesis of coordination complexes $\left[\mathrm{Eu}(2)\left(\mathrm{NO}_{3}\right)_{3}\right]$ and $\left[\mathrm{Eu}(\mathbf{4})\left(\mathrm{NO}_{3}\right)_{3}\right]$.

Figure 5. Molecular structure and atom labeling scheme for $\left[\mathrm{Eu}(4)\left(\mathrm{NO}_{3}\right)_{3}\right]$ with $\mathrm{H}$-atoms omitted. Thermal ellipsoids are shown at the $50 \%$ level.

Figure 6. Americium(III) and europium(III) distribution ratios as a function of the initial nitric acid concentration. Organic phase: 2-, 3-(meso/rac 29/71), OPhDiBCMPO (G) and (I) at $10 \mathrm{mM}$ in 1,2-DCE. Aqueous phase: trace ${ }^{241} \mathrm{Am}$ and $0.1 \mathrm{mM}$ Europium nitrate in nitric acid. $\mathrm{O} / \mathrm{A}=1, \mathrm{~T}$ $=25^{\circ} \mathrm{C}$. 
Figures and Schemes (in order that they appear, captions are provided in manuscript file)

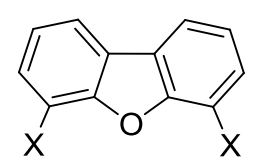

A

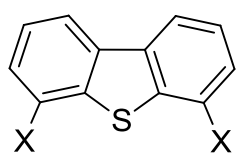

B

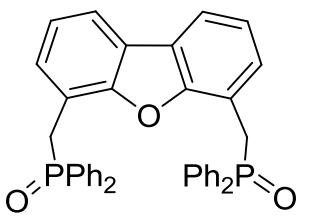

C

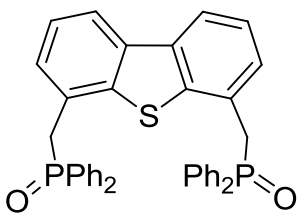

D

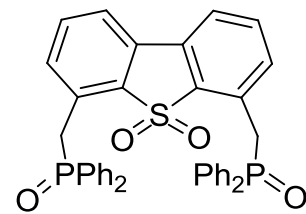

E<smiles></smiles>

$\mathbf{F}$<smiles>[R]NC(=O)CP([R])[R]</smiles>

G<smiles></smiles>

$\mathbf{H}$<smiles></smiles>

I

Figure 1.

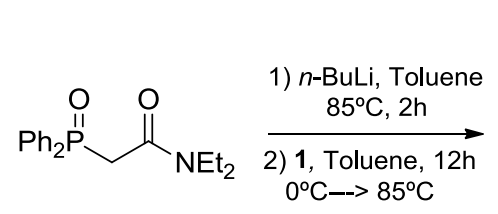

G

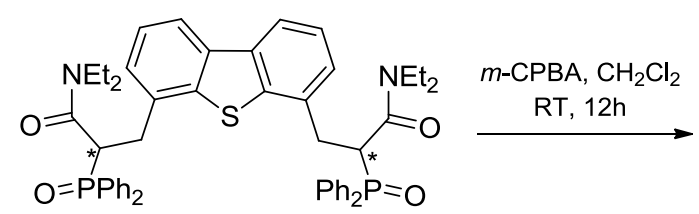

2

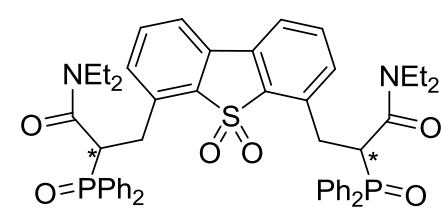

3

\section{Scheme 1.}




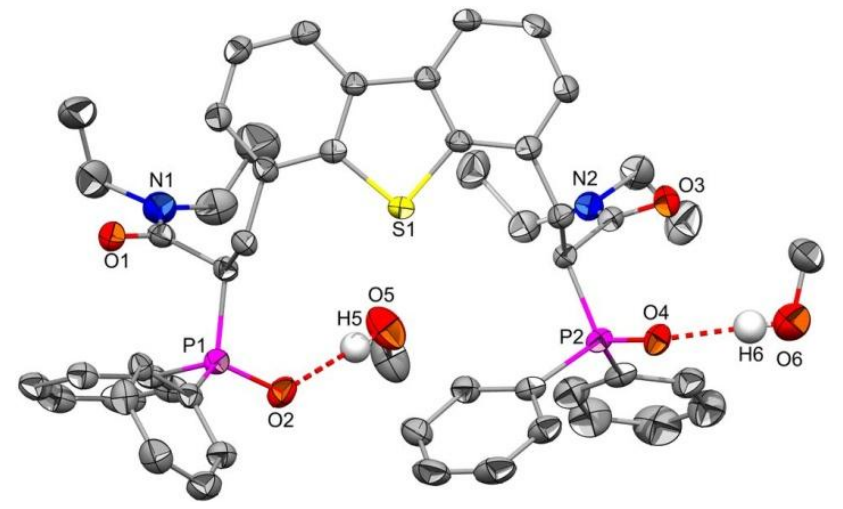

Figure 2. 
a)

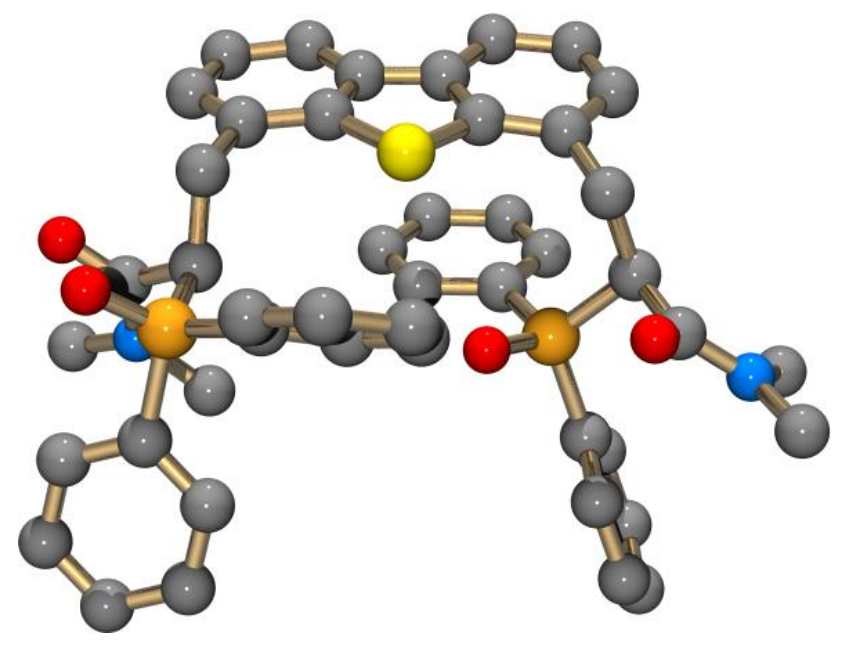

b)

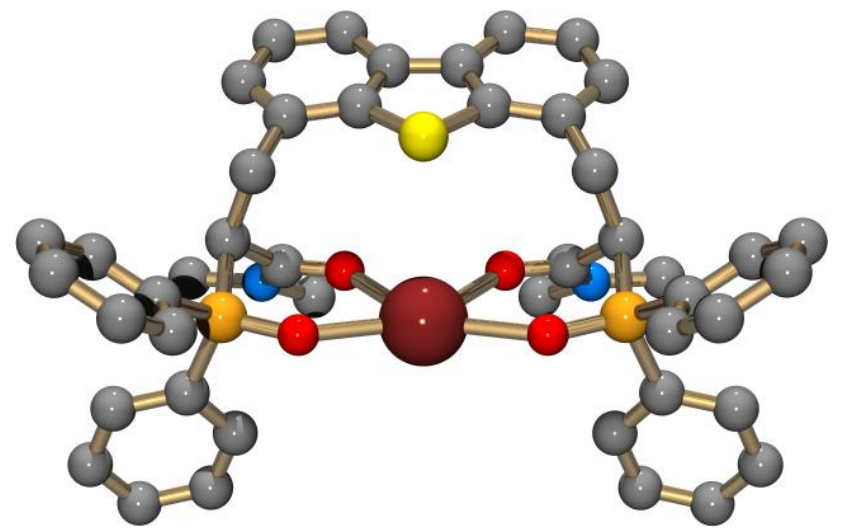

Figure 3. 
a)

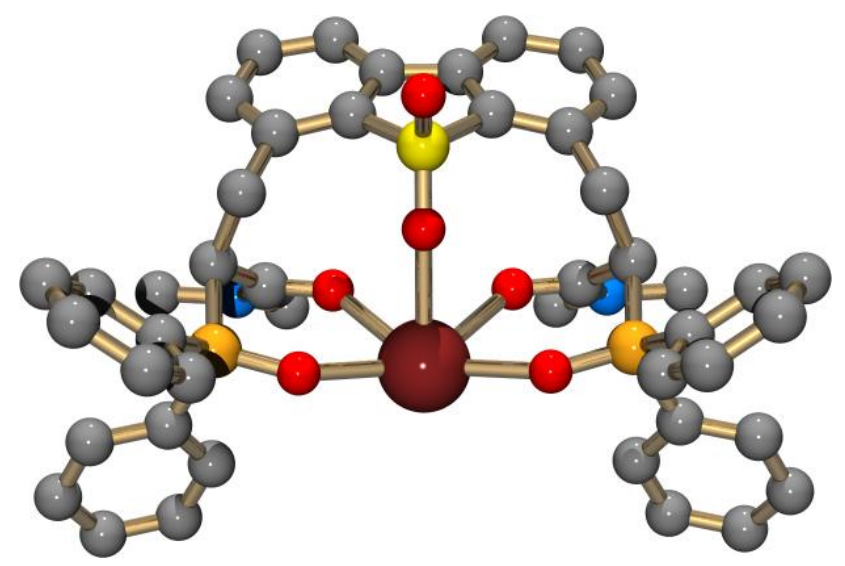

b)

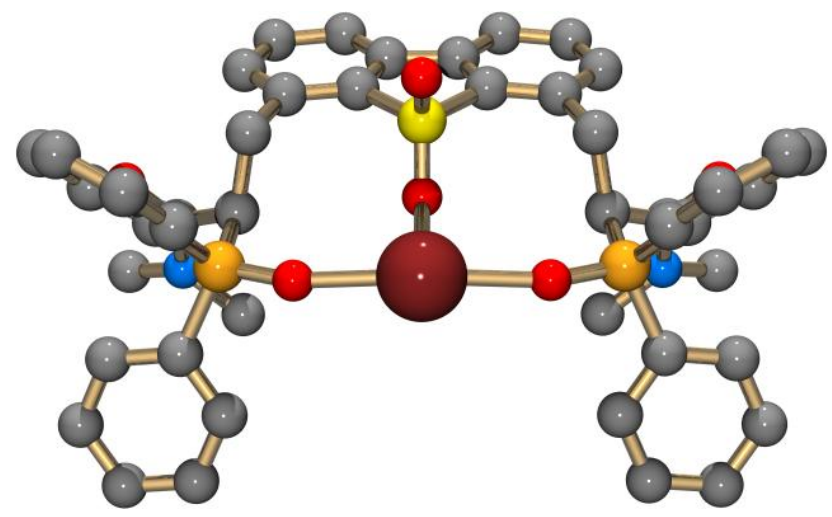

Figure 4. 


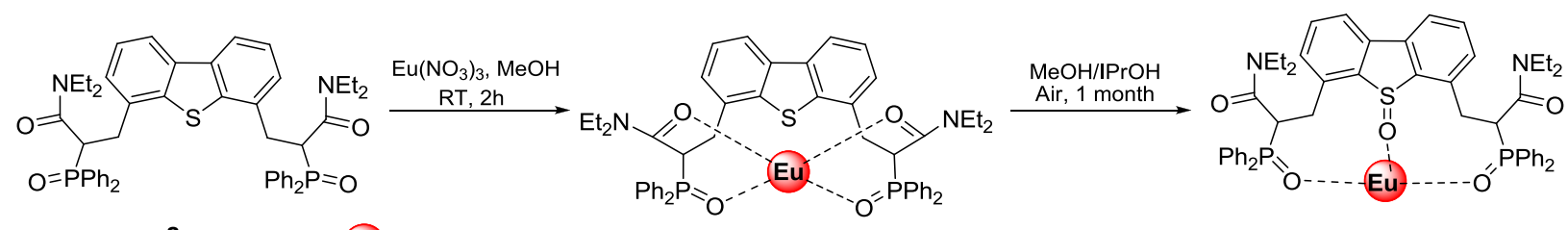

2

EU : $\mathrm{Eu}\left(\mathrm{NO}_{3}\right)_{3}$

Scheme 2.

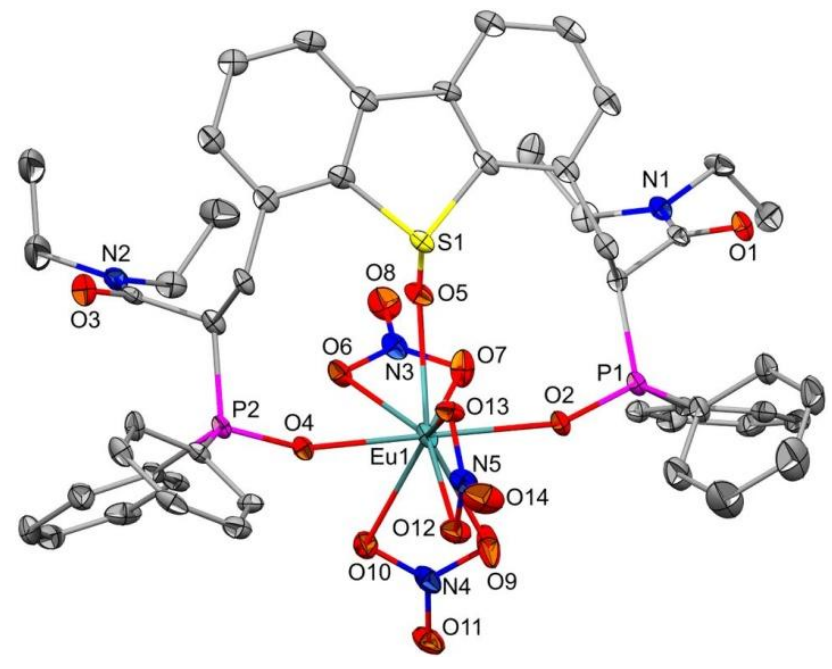

Figure 5. 


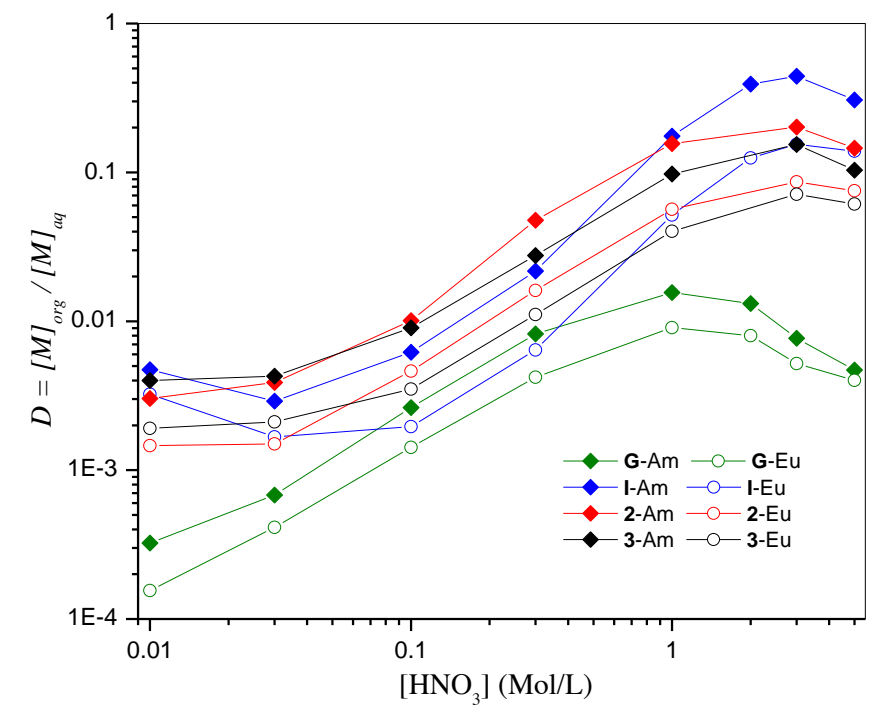

Figure 6. 